\title{
Auctions with external incentives: experimental evidence
}

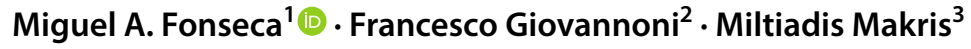

Accepted: 1 July 2020 / Published online: 3 August 2020

(C) The Author(s) 2020

\begin{abstract}
We consider auctions where bidders' valuations are positively correlated with their productivity in a second-stage aftermarket. We test in the lab whether bidders recognize the opportunity to signal their productivity through their bidding and, conditional on them doing so, whether disclosing different information about the auction outcomes affects their signaling behavior. Our results confirm that bidders recognize the signaling opportunities they face and also react to differences in the way their bidding behavior is disclosed, although not always in a way that is consistent with theoretical predictions.
\end{abstract}

Keywords Auctions $\cdot$ Signaling $\cdot$ Disclosure $\cdot$ Experiments

JEL Classification C92 · D44 · D82

\section{Introduction}

Often, bidders care about the reputational effects of their bidding. For instance, this is the case when managers bid on behalf of shareholders for a takeover of another firm. Imagine that the value of the target firm to each bidding firm has a (private) component which depends on their management's ability. That is, the higher this

Miguel A. Fonseca

M.A.Fonseca@exeter.ac.uk

Francesco Giovannoni

francesco.giovannoni@bristol.ac.uk

Miltiadis Makris

m.makris@kent.ac.uk

1 Department of Economics, University of Exeter and NIPE, Universidade do Minho, Streatham Court, Rennes Drive, Exeter EX4 4PU, UK

2 School of Economics, University of Bristol, Priory Road Complex, Priory Road, Bristol BS8 1TU, UK

3 School of Economics, Keynes College, D1.09, University of Kent, Canterbury, Kent CT2 7NP, UK 
ability, the better the potential acquisition would be managed and the more valuable it would be. Thus, how much a bidding manager is willing to pay is a function of her ability as a manager. Insofar as managers' career prospects and future rewards depend on the post-auction inferences of markets about managerial ability to evaluate and manage assets, and managers are aware of this, the type of information that is disclosed at the end of the auction will influence their bidding. In other words, managers with career concerns will use their bids to publicly signal their ability. The same argument applies to bidding for spectrum auctions, sports agents bidding for a free player, or collectors, who also offer consultancy services, when bidding for a work of art to add to their collection.

In such environments, auction disclosure rules that pre-specify the type of information released at the end of the auction become important. They may have an impact on auction revenues, the bidders' careers prospects and/or the level and distribution of post-auction wages and managerial compensations. These effects will in turn influence government revenues from license auctions, the interaction of market discipline and performance of managers of potential targeted firms, the regulation of art auctions, the scope of salary caps and existence of undisclosed fees in sports transfer markets, to mention but a few. The significance of these makes it imperative to understand the effects of various disclosure rules on auction and post-auction outcomes.

This paper is an experimental investigation of the implications of disclosure rules on bidding behavior, auction outcomes and remuneration of bidders' post-auction services. To study these effects, we frame the incentives between the auction and the possible longer-term effects in a setting where bidders valuations in the auction are also linked to their productivity as workers. We chose this setting, which maps closely with the example of takeovers described above, because it is easy to explain to the participants in our experiment. As the structure of the experiment should clarify, however, the incentives in the experiment also apply to all of the examples described above.

Specifically, we consider a setting with two stages. In the first stage, we run sealed-bid first-price auctions for a single object between two bidders. In the second stage, the bidders from the first-price auction take on the role of workers in a labor market where their wages are determined. In the latter market, two firms may hire any number of workers (who can work for only one firm) and each firm bids a wage for each worker's services. The benefits to firms from hiring bidders/workers are the same, and proportional to the bidders' valuations of the auctioned object. This is effectively Bertrand competition between firms for the services of any given worker. Throughout, valuations are private information of workers and at the end of the first stage, the winning worker's identity is publicly disclosed. Treatments differ in terms of the information released to everyone at the end of the auction about submitted bids before the wage-setting market takes place.

An important benefit of this setting is that it maps very closely with the theoretical framework in Giovannoni and Makris (2014), from which we derive predictions. In particular, we consider four disclosure rules. We have disclosure rule $\mathcal{A}$ (for "all"), where all the bids and the corresponding bidder's identity are revealed; disclosure rule $\mathcal{N}$ (for "none") where the winner's identity is revealed but none of 
the bids are; disclosure rule $\mathcal{W}$ (for "winner") where only the winning bid (and the winner's identity) is disclosed, and disclosure rule $\mathcal{S}$ (for "second") where only the losing bid (and the winner's identity) are disclosed. ${ }^{1}$ We also consider as controls the disclosure rule $\mathcal{B}$ (for "base") where no second-stage wage-setting market takes place, and the situation (disclosure rule $\mathcal{T}$, for "transparent") where a second-stage wage-setting market takes place but valuations are revealed at the end of the firststage auction. In both treatments, there is no theoretical scope for signaling through bids.

We address two main questions. The first question is whether bidders recognize the signaling opportunities created by the presence of the aftermarket. If they do recognize these signaling opportunities, the second question is whether their behavior conforms to the different incentives implied by the different disclosure rules. We also ask, to the extent that the results do not conform to the theoretical predictions, what might explain the deviations from predicted behavior.

Our results suggest that subjects' behavior provide a positive answer to the first question. In particular, workers bid higher than they would in the absence of an aftermarket to signal their productivity: we call this overbidding. With respect to the second question, subjects do not show the full sophistication needed for confirming (expected) revenue comparisons across treatments. We show how, for treatments $\mathcal{A}$, $\mathcal{W}$ and $\mathcal{N}$, but not for $\mathcal{S}$, the amount of a particular worker's overbidding is indeed related to how likely it is that such bid is revealed. This shows an understanding of the underlying incentives, with the exception of the $\mathcal{S}$ treatment.

These results imply that signaling incentives in auctions are fairly robust, and the impact of these effects should be taken into account when setting up or studying auction markets. Our results also suggest, however, that precise predictions on the effect of specific disclosure rules should be made with a degree of caution. In particular, we do find that revenue is higher when there are signaling incentives, a natural consequence of overbidding. However, while subjects understand the differences in signaling opportunities across disclosure rules, they do not do so to the extent that revenues are affected as predicted by theory.

For example, if we compare the $\mathcal{W}$ treatment with the $\mathcal{A}$ treatment, theory predicts a steeper bidding function in the former, but overall higher expected revenues in the latter because incentives to overbid across individuals are higher. Our results find that the empirical bidding function in the $\mathcal{W}$ treatment is indeed steeper than that in the $\mathcal{A}$ treatment, but expected revenues are not significantly different across treatments. This indicates that bidders understand the relative differences but not the absolute ones across incentives. Put another way, bidders seem to understand the comparative statics but are not sophisticated enough to conform to the point predictions. We can show that most of these failures can be explained by the behavior of bidders whose valuations are quite low or quite high, whereas bidders with intermediate valuations tend to conform more to theoretical predictions.

\footnotetext{
1 Put another way, because we have two bidders in each auction, in all disclosure rules the identities of the winner and the loser are revealed. Each rule differ solely in the set of bids which are revealed.
} 
There is a theoretical literature that deals with cases where reputational effects distort bidding behavior. Das Varma (2003), Haile (2003), Goeree (2003), and Salmon and Wilson (2008) discuss the effects of external incentives on bidding behavior. Their focus is on the comparison of various price mechanisms for a given disclosure rule. In our experiment, all our treatments instead fix the first-stage price mechanism (first-price auction) and vary the disclosure rules. This is because Giovannoni and Makris (2014) show that in an environment where external incentives introduce solely signaling incentives, disclosure rules are the crucial component in terms of expected revenue comparisons. Katzman and Rhodes-Kropf (2008) and Molnar and Virag (2008) also recognize the importance of disclosure rules but their results are more ambiguous than those in Giovannoni and Makris (2014). ${ }^{2}$ Finally, Dworczak (2017) studies the problem of optimal disclosure rules, allowing for much more generality in the disclosure of information, but does not allow for reputational concerns for the losers in the auction.

Our paper also relates to a few strands of literature within experimental game theory. In the first instance, this work is the latest in a line of research exploring the motives for overbidding in auctions. A long-standing literature on experimental auctions studies the role of informational feedback and overbidding in first-price auctions. Isaac and Walker (1985) first studied this question. They compared the case where the winner's bid was revealed to the case where all bids were revealed; they found more overbidding in the former treatment than the latter. More recently, Dufwenberg and Gneezy (2002) and Ockenfels and Selten (2005) have extended the literature on informational feedback. One possible behavioral explanation as to why different modes of feedback can result in different levels of bidding relative to the risk neutral Nash equilibrium is regret. This behavioral explanation was first proposed by Engelbrecht-Wiggans (1989), and extended by Engelbrecht-Wiggans and Katok (2005). Filiz-Ozbay and Ozbay (2007) propose a model of anticipated regret to explain why different informational conditions lead to overbidding. Another literature that explores overbidding in auctions is that on auctions with resale. Overbidding relative to the "standard" case occurs in this environment because bidders whose private values are low have the opportunity to recoup any losses incurred in the first auction through reselling the object (see Lange et al. 2011; Georganas 2011 and Georganas and Kagel 2011; Filiz-Ozbay et al. 2015; Pagnozzi and Saral 2017, for recent experimental investigations).

In our paper, bid disclosure affects bidding behavior not for behavioral reasons, but as the profit-maximizing response to career concerns. Our paper thus contributes to the relatively small experimental literature on signaling. Miller and Plott (1985) study a product quality signaling game; Cooper et al. (1997) study limit pricing games. More recent studies include Cooper and Kagel (2005; 2009), who study individual vs team play in signaling games, Kübler et al. (2008), who study job market signaling in the lab and Jeitschko and Normann (2012), who study signaling games with deterministic vs stochastic signals. Dodonova and Khoroshilov (2014) examine

\footnotetext{
${ }^{2}$ Giovannoni and Makris (2014) discuss these differences in detail.
} 
the signalling hypothesis proposed by Fishman (1988) behind jump bidding in takeover auctions with entry costs.

The innovation in our paper is that we study signaling through auctions which introduces an additional layer of complexity. In some of our treatments, the information that becomes publicly available depends on the behavior of other agents: when only the winner's bid is disclosed, for example, any bidder is never certain that her bid will be disclosed. Our paper is closely related to Bos et al. (2018), who experimentally investigate the role of an external observer on behavior in a two-player aftermarket. The external observer in their experiment performs the same role as the firms in our experiment, in that payoffs to bidders may depend on the observer's valuation. The experiment varies the auction format (first-price vs. ₹second-price), information to the external observer about the winner's payoffs, and whether the observer's estimates of bidders' private values affects bidders' payoffs. Similar to our results, the authors find that signaling opportunities affect bidding behavior in the auction, even though bidding is not as aggressive as predicted by theory. They also find that the first-price auction when winner's payment is revealed outperforms all other treatments in terms of revenue and efficiency. This paper complements our research in two dimensions. It compares two auction formats under one disclosure rule, while we focus on multiple disclosure rules under the first-price auction. It also considers a different implementation of the aftermarket stage.

In the next section, we introduce the theory and hypotheses behind our experiment. Section 3 describes the experiment and Sect. 4 collects our results. In the latter Section we also provide a discussion of the results. Section 5 concludes while the Appendix contains some more theoretical details as well as detailed instructions for the experiment.

\section{Theory and hypotheses}

Giovannoni and Makris (2014) provide a general analysis of the theoretical setting, but in that paper, the second-stage market is not explicitly modeled. In our experimental analysis, however, we have subjects explicitly participating in the secondstage market. Therefore, in this paper, we need to formally model these interactions. In this section we introduce the model, and describe the main results together with the hypotheses we will test in the experiments. We leave some of the details for the Appendix.

The Giovannoni and Makris (2014) framework applies to many different situations where bidding behavior, by revealing information about the underlying valuations of the bidders, may also affect the latter's opportunities in a future market interaction. For example, consultants in art markets will be aware that their bidding (advice) will reveal their expertise to future clients, or CEOs of firms that take over another firm will know that their bids will be a signal of their managerial ability. ${ }^{3}$ For the purposes of the experiment, however, and to make the underlying situations as simple and transparent

\footnotetext{
3 See Giovannoni and Makris (2014) for further discussion of possible applications of their framework.
} 
as possible to participants, we consider a situation where bidders are "workers" whose valuation for a good in the first-stage auction is also an indicator of the productivity in a second-stage labor market where they are employed by "firms".

In particular, we have two auction stages with two bidders in each stage. In the first stage there is a first-price auction where two "workers" bid for a single unit of an indivisible good in a standard independent private value (IPV) setting. Each bidder $i \in\{1,2\}$ has a valuation $x_{i}$ for the good and the valuations are independently and uniformly distributed on [0,100]. Let $b_{i}$ be the bid of worker $i$. We denote $\mathbf{x}=\left(x_{1}, x_{2}\right)$ and $\mathbf{b}=\left(b_{1}, b_{2}\right)$, while capital letters denote random variables and small letters their realizations.

In the second stage, there is a market ("the aftermarket") that determines which worker is employed, and at what wage, by existing firms. Firms are symmetric; their valuation for worker $i$ 's employment is $\alpha x_{i}, \alpha>0$, while they obtain zero if they do not employ a worker. Thus, we assume that a worker's willingness to pay for the object in the first-stage auction is proportional to her productivity for firms in the second period.

We will consider several versions of this model, corresponding to different treatments in our experiment and these versions differ from each other according to how much information is publicly disclosed at the end of the first-stage auction about workers' valuations. Throughout, we will consider Perfect Bayesian Equilibria where, in the first-stage auctions, bidding functions are symmetric and monotone. We will simply refer to them as equilibria.

\subsection{Disclosure rules}

We begin with describing the aftermarket, which will be the basis for our comparisons across different disclosure procedures. It consists of two parallel first-price auctions. In second-stage auction 1, two "firms" $A$ and $B$ bid for worker 1's employment while in second-stage auction 2, the same two "firms" $A$ and $B$ bid for worker 2's employment. Workers, at this stage, simply receive the highest bid in second-stage auction $i$ as a wage. Let $w_{l}^{i}$ be the wage offer from firm $l \in\{A, B\}$ to worker $i$ (i.e. firm $l^{\prime} s$ bid in second-stage auction $i$ ) and let $\mathbf{w}_{l}=\left(w_{l}^{1}, w_{l}^{2}\right)$ be the wage profile offered by firm $l$. Then, the utility for firm $l$ in this stage if she offers $\mathbf{w}_{l}$ and the other firm $m$ offers $\mathbf{w}_{m}$ is equal to

$$
\begin{aligned}
u_{l}\left(\mathbf{w}_{l}, \mathbf{w}_{m}, \mathbf{x}\right)= & \left.1_{\left(w_{l}^{1}>w_{m}^{1}\right)}+\frac{1}{2} \times 1_{\left(w_{l}^{1}=w_{m}^{1}\right)}\right]\left(\alpha x_{1}-w_{l}^{1}\right) \\
& +\left[1_{\left(w_{l}^{2}>w_{m}^{2}\right)}+\frac{1}{2} \times 1_{\left(w_{l}^{2}=w_{m}^{2}\right)}\right]\left(\alpha x_{2}-w_{l}^{2}\right)
\end{aligned}
$$

where $1_{A}$ represents the indicator function that takes value 1 iff $A$ is true. Given the above, the total utility for worker $i$ over the two stages, given $x_{i}, \mathbf{b}=\left(b_{i}, b_{j}\right), j \neq i$, $j=1,2$, and $\mathbf{w}^{i}=\left(w_{A}^{i}, w_{B}^{i}\right)$ is equal to

$$
U_{i}\left(\mathbf{w}^{i}, \mathbf{b}, x_{i}\right)=\left[1_{\left(b_{i}>b_{j}\right)}+\frac{1}{2} \times 1_{\left(b_{i}=b_{j}\right)}\right]\left(x_{i}-b_{i}\right)+\max \left\{w_{A}^{i}, w_{B}^{i}\right\}
$$


Note that winning or losing the first-period auction has no consequence for the second-stage wages in itself. However, as we shall discuss shortly, it may affect what firms know about the workers' valuations and hence the wage offers they will be willing to make. We will denote with $\mathcal{I}^{\phi}$ the information available to everyone in the second-stage market under disclosure rule $\phi$. Since this is publicly available information, it will be common knowledge amongst the firms and the workers. Let $\omega \in\{1,2\}$ denote the winner of the first-stage auction and $-\omega$ denote the loser. The disclosure rules are:

1. Transparent: $\phi=\mathcal{T}$. Here $x_{1}$ and $x_{2}$ are publicly revealed and so $\mathcal{I}^{\mathcal{T}}=\mathbf{x}$.

2. All bids: $\phi=\mathcal{A}$. Here $b_{1}$ and $b_{2}$ are publicly revealed and so $\mathcal{I}^{\mathcal{A}}=(\omega, \mathbf{b})$.

3. Winner's bid: $\phi=\mathcal{W}$. Here only the identity of the winner and her bid are publicly revealed and so $\mathcal{I}^{\mathcal{W}}=\left(\omega, b_{\omega}\right)$.

4. Second bid: $\phi=\mathcal{S}$. Here only the identity of the winner and the loser's bid are publicly revealed and so $\mathcal{I}^{\mathcal{S}}=\left(\omega, b_{-\omega}\right)$.

5. No bids: $\phi=\mathcal{N}$. Here only the identity of the winner is publicly revealed and so $\mathcal{I}^{\mathcal{N}}=\omega$.

We also consider the benchmark case $\phi=\mathcal{B}$, where no aftermarket exists, which corresponds to the standard IPV setting. The information available at the end of the auction is obviously irrelevant in this case. ${ }^{4}$

We start our analysis from the second stage. Here the uninformed parties (the firms) make the offers in the second-stage auctions. Risk neutrality and independence of the valuations mean that the value of employing a worker is a fraction $\alpha$ of the worker's valuation of the good in the first stage. Since information at the end of the first-stage auction is publicly available, both firms form the same expectation, $E\left(X_{i} \mid \mathcal{I}^{\phi}\right)$, for each worker $i$, when they contemplate their offers. The following proposition follows immediately:

Proposition In any equilibrium, and conditional on the disclosure rule $\phi$, there is a unique profile of wages $\left(\mathbf{w}_{A}(\phi), \mathbf{w}_{B}(\phi)\right)$ offered by firms in the aftermarket, where for each worker $i=1,2$

$$
w_{A}^{i}(\phi)=w_{B}^{i}(\phi)=\alpha E\left(X_{i} \mid \mathcal{I}^{\phi}\right)
$$

The intuition here is that firms are involved, in effect, in symmetric Bertrand competition. As a result, workers are able to extract all the expected (from the firms' point of view) surplus they can generate for firms. We can now turn to the study of the first-stage auction. Given the proposition, the procedure follows that of Giovannoni and Makris (2014), which we summarize here (more details are given in the Appendix). The analysis entails first putting a simple restriction on off-the-equilibrium-path beliefs, which in turn allows us to define bidder effective valuations under

\footnotetext{
${ }^{4}$ Some auctions can be even more secretive, so that the identity of the winner is unknown. Obviously, in such cases there is no scope for using the first-stage auction as a signaling device.
} 


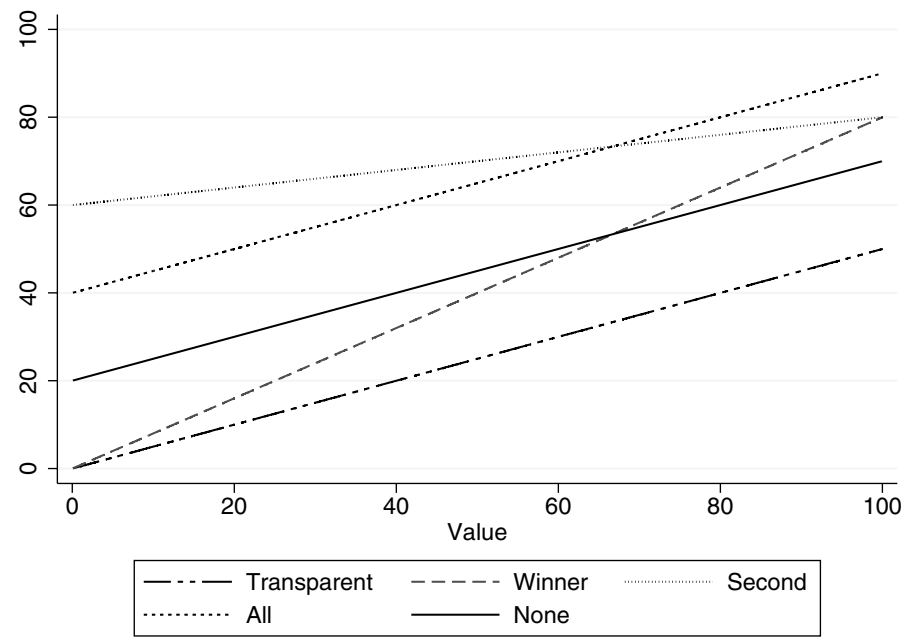

Fig. 1 Theoretical bidding functions

each disclosure rule. An effective valuation is a function of the standard valuation $x_{i}$ that captures all that is at stake for a bidder in the first-stage auction given equilibrium play in the aftermarket. In more detail, we have the direct utility from winning the auction $x_{i}$, but also the reputational returns that $i$ can expect in the second-stage auction(s) as a function of her valuation. These reputational returns are divided into two further components: one that captures the net reputational gain to the bidder from winning the auction, and one that captures the additional reputational net gain from marginally increasing the bid. As shown in Giovannoni and Makris (2014), the optimal bidding function in the first-stage auction is the standard first-price bidding function in the IPV setting but with effective valuations replacing standard valuations. Letting $\beta^{\phi}$ denote such bidding functions, we get that the equilibrium bidding functions are:

$$
\begin{aligned}
& \beta^{\mathcal{B}}\left(x_{i}\right)=\beta^{\mathcal{T}}\left(x_{i}\right)=\frac{1}{2} x_{i} ; \\
& \beta^{\mathcal{A}}\left(x_{i}\right)=\frac{1}{2} x_{i}+100 \alpha ; \\
& \beta^{\mathcal{W}}\left(x_{i}\right)=\frac{1}{2}\left(1+\frac{3}{2} \alpha\right) x_{i} ; \\
& \beta^{\mathcal{S}}\left(x_{i}\right)=\frac{1}{2}\left(1-\frac{3}{2} \alpha\right) x_{i}+150 \alpha ; \\
& \beta^{\mathcal{N}}\left(x_{i}\right)=\frac{1}{2} x_{i}+50 \alpha
\end{aligned}
$$

Figure 1 plots the theoretical bidding functions. The intuition for the bidding functions $\beta^{\mathcal{B}}$ and $\beta^{\mathcal{T}}$ is straightforward: in the first case there is no aftermarket and we have the standard IPV result. In the second case, valuations are publicly revealed 
at the end of the first-stage auction, and so bidders have no incentive to use bids as a signaling device. As a consequence, we obtain again the behavior of the standard IPV setting.

All other disclosure rules imply overbidding relative to $\beta^{\mathcal{B}}$ and $\beta^{\mathcal{T}}$ because now being perceived to have high valuations is beneficial. ${ }^{5}$ Furthermore, the way overbidding obtains depends on the disclosure rule. To understand how overbidding is shaped, we begin with a comparison between $\beta^{\mathcal{A}}$ and $\beta^{\mathcal{W}}$. For $\beta^{\mathcal{A}}$, note first that in a monotone equilibrium bids reveal exactly a bidder's valuation and so other bidders' bids have no impact on reputational returns. In contrast, in auctions where the disclosure rule is $\mathcal{W}$, winning or losing does matter for inferences about $x_{i}$ because if $i$ wins then $b_{i}$ becomes known, while if $i$ loses then firms believe $b_{i}$ to be below the competing (disclosed) bid. In addition to the reputational gain from winning, there is also a reputational gain (relative to the increase in the likelihood of winning the auction) for bidder $i$ from increasing her bid marginally, because, by doing so, she might increase marginally the perception of firm(s) about her valuation.

For disclosure rules $\mathcal{A}$ and $\mathcal{W}$, this relative gain is the same conditional on own bid being disclosed. However, in the former case, all bids are always disclosed, while in the latter case, the only disclosed bid is the winner's. The result is that in auctions where the disclosure rule is $\mathcal{A}$, bidders with different valuations have similar incentives for overbidding. With disclosure rule $\mathcal{W}$, in contrast, the incentive to overbid is much higher for workers with high valuations (who are more likely to win and have their precise bids publicly revealed) than for workers with low valuations (who are more likely to lose and for whom all that will be known is that their bid is below the winner's bid). ${ }^{6}$

The intuition for $\mathcal{S}$ auctions is the opposite to that in $\mathcal{W}$ auctions: now it is bidders with low valuations whose bids are more likely to be disclosed and such bidders have a greater incentive to overbid. ${ }^{7}$ Finally, with disclosure rule $\mathcal{N}$, only the identity of the winner is disclosed so that signaling only comes from winning or losing the auction. In particular, because none of the bids is disclosed, the net reputational gain from winning the auction must be constant, and so bidders of all valuations have the same incentive to overbid. Still, there is less overbidding under $\mathcal{N}$ than under $\mathcal{A}$ (where incentives to overbid are also constant across types). Under disclosure rule $\mathcal{N}$, no bid is ever disclosed and thereby the relative net reputational returns bidders can expect from marginally increasing their bid do not exist with disclosure rule $\mathcal{N}$.

\footnotetext{
${ }^{5}$ Giovannoni and Makris (2014) show that if being perceived to have a low valuation is beneficial then underbidding will occur in equilibrium. The same could be obtained here by assuming that worker productivity for the firm is $\alpha\left(100-x_{i}\right)$.

6 The fact that in $\mathcal{A}$ auctions the overbidding incentives are exactly the same across valuations is a consequence of the fact that we have two bidders and a uniform distribution (which is also responsible for the linearity in the bidding functions).

7 Thus, for disclosure rule $\mathcal{S}$ the incentive to overbid for low types "flattens" the bidding function. It is easy to see that these incentives cannot be too great otherwise the bidding function would no longer be increasing and the equilibrium we focus on would not exist. With our parameterization this means that we need $\alpha<\frac{2}{3}$.
} 
Finally, it is also easy to calculate expected revenues in each treatment using the formula

$$
E R^{\phi}=2 \int_{0}^{100} \beta^{\phi}\left(x_{i}\right)\left(\frac{x_{i}}{10000}\right) d x_{i}=\left\{\begin{array}{lll}
\frac{100}{3} & \text { if } & \phi=\mathcal{B}, \mathcal{T} \\
\frac{100}{3}+100 \alpha & \text { if } & \phi=\mathcal{A}, \mathcal{S} \\
\frac{100}{3}+50 \alpha & \text { if } & \phi=\mathcal{W}, \mathcal{N}
\end{array}\right\}
$$

We summarize these results in the following set of hypotheses. Our two main points of interest in the first-stage auction are i) whether there is overbidding as predicted by the theory and ii) whether, conditional on such overbidding, the comparative statics for disclosure rules $\mathcal{A}, \mathcal{S}, \mathcal{W}, \mathcal{N}$ apply. We begin by looking at expected revenues:

Hypothesis 1 Expected revenues are highest in the $\mathcal{A}$ and $\mathcal{S}$ treatments, and lowest in the $\mathcal{B}$ and $\mathcal{T}$ treatments, with the $\mathcal{W}$ and $\mathcal{N}$ treatments being the intermediate case.

Hypothesis 1 is not, however, the only possible test of the theory. Even if our results confirm the hypothesis, this may happen with bidding functions that differ significantly from the predicted ones. As is well known in the experimental literature on auctions (Kagel 1995; Kagel and Levin 2008), bidding generally does not conform to point predictions made by the theory. Thus, we will also consider a different hypothesis that compares bidding functions across different disclosure rules qualitatively, and allows us to see whether bidders understand the different nature of the signaling opportunities generated by the type of disclosure they face. Our theoretical bidding functions are linear in valuations and so can be fully summarized by the slope and their vertical intercept. Simple inspection of the slope and vertical intercept of each of these bidding functions will then give predictions for how low types should bid in one disclosure rule over another and how rapidly bids should increase in one disclosure rule over another as valuations increase:

Hypothesis 2 (a) The empirical bidding functions for the treatment are ranked as follows in terms of slope: $\mathcal{W}>\mathcal{B}=\mathcal{T}=\mathcal{A}=\mathcal{N}>\mathcal{S}$. (b) The empirical bidding functions for the treatment are ranked as follows in terms of intercept: $\mathcal{S}>\mathcal{A}>\mathcal{N}>\mathcal{W}=\mathcal{B}=\mathcal{T}$.

Our model also generates predictions with respect to second-stage outcomes. We first look at workers' wages. Recall that wages should be equal to the expected productivity of each worker (conditional on the publicly available information at the end of the first-stage auction). We can then write wages $w_{i}^{\phi}$ for $i$ as a function of her bid $b_{i}$ and her opponent's bid $b_{j}{ }^{8}$ :

\footnotetext{
${ }^{8}$ See the appendix for details, keeping in mind that in the $\mathcal{T}$ treatments, the valuations are known to the firms so that bids are irrelevant. Also, note that in the experimental setting we cannot in principle exclude that two workers bid the same amount in the first-stage auction and this creates the issue of how to define a winner in the event of a tie. This matters particularly for wage determination with disclosure rules $\mathcal{W}, \mathcal{S}$ and $\mathcal{N}$. We resolve the problem by determining the winner via a lottery and providing the information according to the disclosure rule. For example, with disclosure rule $\mathcal{W}$, if $b_{i}=b_{j}$ but $i$ wins the lottery, only her bid is disclosed.
} 


$$
\begin{aligned}
w_{i}^{\mathcal{T}}\left(x_{i}, x_{j}\right) & =\alpha x_{i} ; \\
w_{i}^{\mathcal{A}}\left(b_{i}, b_{j}\right) & =2 \alpha b_{i}-200 \alpha^{2} ; \\
w_{i}^{\mathcal{W}}\left(b_{i}, b_{j}\right) & =\left\{\begin{array}{c}
\frac{4 \alpha b_{i}}{2+3 \alpha} \text { if } i \text { wins } \\
\frac{2 \alpha b_{j}}{2+3 \alpha} \text { if } i \text { loses }
\end{array}\right. \\
w_{i}^{\mathcal{S}}\left(b_{i}, b_{j}\right) & =\left\{\begin{array}{c}
2 \alpha \frac{b_{j}+50-225 \alpha}{2-3 \alpha} \text { if } i \text { wins } \\
4 \alpha \frac{b_{i}-150 \alpha}{2-3 \alpha} \quad \text { if } i \text { loses }
\end{array} ;\right. \\
w_{i}^{\mathcal{N}}\left(b_{i}, b_{j}\right) & =\left\{\begin{array}{cc}
75 \alpha & \text { if } i \text { wins } \\
25 \alpha & \text { if } \quad i \text { loses }
\end{array}\right.
\end{aligned}
$$

These results can be summarized by a second set of hypotheses. We begin with a simple consequence of the fact that across disclosure rules, we predict bidding functions that are increasing in valuations and we disclose the identity of the winner. Since we also predict that wages will be a function of expected valuations, then we expect:

Hypothesis 3 Across disclosure rules, winners receive higher wages than losers.

To test more precise predictions regarding wages, we again rely on comparisons across disclosure rules: ${ }^{9}$

Hypothesis 4 With disclosure rules $\mathcal{T}$ and $\mathcal{A}$, the two workers share the same wage function. ${ }^{10}$ With disclosure rule $\mathcal{W}$, the winner's wage is more responsive than the loser's wage to the winner's bid, while with disclosure rule $\mathcal{S}$ the loser's wage is more responsive than the winner's wage to the loser's bid. ${ }^{11}$

These predictions are intuitive if one recalls that wages are only a function of the aftermarket's expectation about workers' productivity. The immediate consequence is that with disclosure rules $\mathcal{T}$ and $\mathcal{A}$, a worker's wage is based on her own valuation or bid, while with disclosure rules $\mathcal{W}$ or $\mathcal{S}$, the wage must be based on the only bid that is observed: respectively, the winner's or the loser's. In each of these last two cases, the impact on wages will depend on whose bid is the one that is disclosed. As one would expect, the marginal effect of the publicly observed bid on the wage of the bidding worker must be stronger than the marginal effect on her opponent's

\footnotetext{
${ }^{9}$ Recall that in the $\mathcal{B}$ treatment, there is no aftermarket.

${ }^{10}$ Of course, in the $\mathcal{T}$ case, such wage function is a function of the bidder's valuation $x_{i}$ while in the $\mathcal{A}$ case, it must be a function of her bid $b_{i}$. In fact, $w_{i}^{\mathcal{A}}\left(\beta^{\mathcal{A}}\left(x_{i}\right), \beta^{\mathcal{A}}\left(x_{j}\right)\right)=w_{i}^{\mathcal{T}}\left(x_{i}, x_{j}\right)$.

${ }^{11}$ In the $\mathcal{N}$ treatment, bids are not disclosed, so the wage functions under this treatment cannot be part of the comparisons in Hypothesis 4.
} 
Table 1 Experimental design

\begin{tabular}{llllll}
\hline $\mathcal{T}$ & $\mathcal{W}$ & $\mathcal{S}$ & $\mathcal{A}$ & $\mathcal{N}$ & $\mathcal{B}$ \\
\hline$(3,36)$ & $(3,36)$ & $(3,36)$ & $(3,36)$ & $(3,36)$ & $(3,36)$ \\
\hline
\end{tabular}

(\# sessions, \# subjects)

wage. This explains the differences in the wage functions of the winner and loser under $\mathcal{W}$ or $\mathcal{S}$.

Finally, one last testable implication of our model is that it predicts that, conditional on a given expected valuation, all the surplus (as expected by firms) will go to the workers. In other words:

Hypothesis 5 Under all disclosure rules, firms will make zero profits.

Notice that this hypothesis requires both that firms can form correct beliefs about the workers' valuations and that they conform to Bertrand competition. In the case of disclosure rules $\mathcal{T}$, firms know the workers' valuations while in all other cases, they do not and have to form beliefs relying on disclosed bidding behavior. We will use this difference to investigate Hypothesis 5 further.

\section{Experimental design and procedures}

Our experiment implements the model laid out in Section 2 in a between-subjects design. Table 1 outlines the experimental design. We consider six treatments. Five treatments differ in the information revealed after the first stage auction: in $\mathcal{T}$, both workers' private values are revealed; in $\mathcal{W}$, only the winning worker's bid is revealed; in $\mathcal{S}$, only the losing worker's bid is revealed; in $\mathcal{A}$, both workers' bids are revealed; and in $\mathcal{N}$, neither values nor bids are revealed. Finally, in $\mathcal{B}$, we consider a standard first price auction without an aftermarket.

Upon arrival to the laboratory, subjects sat in individual computer booths. Verbal communication was not allowed at any time. We gave written copies of the instruction sets to subjects (reproduced in the Appendix), and we publicly announced that everybody in a given role was reading the same set of instructions. Subjects had a maximum of $10 \mathrm{~min}$ in which to read the instructions; after that time elapsed, subjects had the opportunity to ask clarification questions in private. Once all queries were answered, the experiment started.

Subjects were assigned to the role of firm or worker at the beginning of the experiment, and they kept their roles until the end of the experiment. Subjects had five practice periods in which to familiarize themselves with the software interface and the auction environment. Once the five practice periods were concluded, the experimenters made a public announcement that all further rounds would be incentivized. In every period of the experiment (including the practice periods), subjects were randomly matched with other participants in the session. 
In all treatments, the first-stage auction had two workers bidding for a prize, whose value was an i.i.d. draw from a uniform distribution with support $\{0.01,0.02, \ldots, 100.00\}$, as is standard in the experimental literature on privatevalue auctions (c.f. Goeree and Holt 2002; Güth et al. 2005). Applying an i.i.d. draw for each participant in a given session is closest to the spirit of the theory. When the support of the distribution of private values is large relative to the number of draws, it ensures that the results will be based on (in expectation) a larger set of realizations. The main alternative to this approach would be to use a pre-randomized sequence of private values. Its main advantage is comparability of behavior, and less variability across sessions. This advantage translates into more statistical power. However, given that the set of possible private values is very large $(10,000$ possible values), we feel that using the same sequence of only 35 realizations per bidder would make our results unrepresentative.

Worker bids could be made from the set $\{0.00,0.01,0.02, \ldots, 100.00\}{ }^{12}$ After both workers placed their bids, a screen provided feedback to the workers and firms; the type of feedback was a function of the disclosure rule. The second-stage auction followed the feedback screen. The two firms made a wage offer for each of the two workers, also from the set $\{0.00,0.01,0.02, \ldots, 100.00\}$. A worker would be assigned to the firm who made the highest wage offer; it was therefore possible for one firm to hire both workers. The value to firms from hiring a worker was equal to $40 \%$ of the worker's private valuation of the object on sale in the first-stage auction. In other words, the value of the parameter $\alpha$ was set to 0.4 .

There were a total of 35 incentivized periods in the experiment. The payment was the payoff from three randomly picked periods, plus a show-up fee. Since our theory predicted firms would earn significantly lower payoffs than workers, we set the show-up fee for workers to be equal to $£ 5$, and the show-up fee for firms to be $£ 10$. We conducted three sessions with 12 participants in each session. Each session implemented one condition. No participant took part in more than one session.

Our subjects were recruited from a pool of volunteers, all of whom were undergraduate students from a wide range of disciplines using the lab's ORSEE system (Greiner 2015). The experiment was programmed using Z-Tree (Fischbacher 2007). A total of 216 subjects took part, none of whom had ever taken part in an auction or market experiment before. Sessions lasted on average 90 minutes, and the average payment was approximately $£ 18.50$ (which is more than twice the minimum hourly wage in the UK).

\footnotetext{
12 We only allowed bidding up to the maximum private value, as this was comfortably in excess of the maximum predicted bid: 90 (with a private value of 100 in $\mathcal{A}$. It is possible that this could have censored our data if there were bidders who wished to bid in excess of 100 . We only recorded 23 out of 4410 (less than $0.5 \%$ ) observations with bids in excess of 90 and only 1 bid of 100 .
} 
Table 2 First-stage auction revenue

\begin{tabular}{lllll}
\hline DV: Stage 1 revenue & $(1)$ & & $(2)$ & \\
\hline $\mathcal{T}$ & -0.41 & $(1.95)$ & -0.41 & $(1.95)$ \\
$\mathcal{W}$ & $5.91^{* * *}$ & $(1.03)$ & $5.91^{* * *}$ & $(1.03)$ \\
$\mathcal{S}$ & 2.64 & $(1.88)$ & 2.64 & $(1.88)$ \\
$\mathcal{A}$ & $5.68^{* * *}$ & $(1.83)$ & $5.68^{* * *}$ & $(1.83)$ \\
$\mathcal{N}$ & 4.50 & $(2.84)$ & 4.50 & $(2.84)$ \\
Period & - & & $-0.07^{* *}$ & $(0.03)$ \\
Constant & 50.00 & $(0.99)$ & 51.30 & $(1.14)$ \\
$\mathrm{N}$ & 4,410 & & 4410 & \\
$R^{2}$ & 0.02 & & 0.02 & \\
\hline
\end{tabular}

Omitted category is $\mathcal{B}$. In the $\mathcal{N}$ treatment we collected 12 workers per session, as there were no firms. In all other treatments, we collected only 6 workers per session. As a result, $N=(35 \times 6 \times 15)+(35 \times 12 \times 3)=4410$

${ }^{* * *},{ }^{* *}: p<0.01, p<0.05$. Session-level clustered SEs in parentheses

\section{Results}

The unit of analysis is the bidding decision by an individual (firm or worker) in an incentivized experimental period (our analysis is robust to the inclusion of the five practice periods), or an individual's per period revenue. Unless otherwise noted, we will employ random effects estimators with clustered standard errors at the session level, to account for the random matching protocol. We also consider extended models that include a linear time trend. We replicate our analysis by considering only the final 20 rounds, to control for any learning that may have taken place in the first third of the experiment. Our results are robust both quantitatively and qualitatively. Results are available upon request.

\subsection{First-stage auction bidding}

We start by looking at revenue in the first-stage auction, summarized in Table $2 .{ }^{13}$

Result 1: Limited disclosure generally leads to overbidding but there is weak support for our revenue predictions.

Support: We find partial confirmation of our theoretical predictions. Hypothesis 1 stated revenues should be lowest in $\mathcal{T}$ and $\mathcal{B}$. Average revenue is indeed very similar in $\mathcal{T}$ and $\mathcal{B}\left(\chi^{2}(1)=0.04, p=0.836\right)$, as predicted. While average revenue in all other treatments is nominally higher, it is only significantly higher in the case of

\footnotetext{
13 The attentive reader may wonder why the sample size is 4410 . Since there were no firms in the $\mathcal{N}$ treatment, we were able to collect 12 workers bidding in the first stage auction, as opposed to only 6 in the other five treatments. This means that we collected $(35 \times 6 \times 15)+(35 \times 12 \times 3)=4410$ observations.
} 
Table 3 Estimated workers' bidding functions in each treatment

\begin{tabular}{lllllll}
\hline DV: $b_{i, t}$ & $\mathcal{T}$ & $\mathcal{W}$ & $\mathcal{A}$ & $\mathcal{S}$ & $\mathcal{N}$ & $\mathcal{B}$ \\
\hline$x_{i, t}$ & $0.68^{* * *}$ & $0.78^{* * *}$ & $0.71^{* * *}$ & $0.67^{* * *}$ & $0.72^{* * *}$ & $0.75^{* * *}$ \\
& {$[0.50]$} & {$[0.80]$} & {$[0.50]$} & {$[0.20]$} & {$[0.5]$} & {$[0.5]$} \\
& $(0.04)$ & $(0.01)$ & $(0.04)$ & $(0.01)$ & $(0.003)$ & $(0.02)$ \\
Constant & $2.70^{* *}$ & $3.49^{* * *}$ & $9.08^{* * *}$ & $7.71^{* * *}$ & $6.69^{* * *}$ & 0.31 \\
& {$[0]$} & {$[0]$} & {$[40]$} & {$[60]$} & {$[0]$} & {$[0]$} \\
& $(1.12)$ & $(0.45)$ & $(1.34)$ & $(1.24)$ & $(1.51)$ & $(0.33)$ \\
$R^{2}: 0.87$ & & & & & & \\
\hline
\end{tabular}

Predicted coefficients in square brackets

Session-clustered SEs in parentheses. ${ }^{* * *},{ }^{* *} p<0.01, p<0.05$

$\mathcal{W}\left(\mathcal{W}=\mathcal{T}: \chi^{2}(1)=13.74, p<0.001 ; \mathcal{W}=\mathcal{B}: \chi^{2}(1)=32.77, p<0.001\right)$ and $\mathcal{A}$ $\left(\mathcal{A}=\mathcal{T}: \chi^{2}(1)=7.15, p=0.008 ; \mathcal{A}=\mathcal{B}: \chi^{2}(1)=9.64, p=0.002\right)$. In all other cases, we find no significant differences (a full breakdown of all tests is in Table 8 in the Appendix) between treatments without signaling opportunities $(\mathcal{B}$ and $\mathcal{T}$ ) and treatment with such opportunities (all others). With respect to the latter group of treatments, with the exception of $\mathcal{W}$ and $\mathcal{S}\left(\chi^{2}(1)=4.06, p=0.044\right)$, we find no significant differences in average revenue across treatments.

While our theory predicted revenue equivalence between some disclosure rules, it did not predict it for others. We now turn to the bidding functions themselves. Table 3 shows results from regressions of the bid placed by worker $i$ in experimental period $t, b_{i, t}$, on that worker's private value in that period, $X_{i, t}$, and dummy interactions with the relevant treatments and their corresponding dummy intercepts. In order to facilitate the interpretation of the table and for ease of comparison with point predictions, we present estimated coefficients directly, rather than the estimated dummy interaction coefficients. Table 9 in the Appendix shows results from the same regression in the traditional format. ${ }^{14}$

Result 2: The empirical bidding functions are ranked in terms of slopes as follows: $\mathcal{W}>\mathcal{B}=\mathcal{N}=\mathcal{A}=\mathcal{T}=\mathcal{S}$. The empirical bidding functions are ranked in terms of intercepts as follows: $\mathcal{A}=\mathcal{S}=\mathcal{N}>\mathcal{W}=\mathcal{T}>\mathcal{B}$.

Support: We start by comparing estimates of slopes. The first part of Hypothesis 2 pertains to the equality of estimated slope coefficients in the $\mathcal{B}, \mathcal{T}, \mathcal{N}$ and $\mathcal{A}$ treatments. We fail to reject the null of equality for all pairwise tests of equality slope of slope coefficients $\left(\chi^{2}(1) \leq 1.96, p \geq 0.161\right)$ (see Table 10 for all pairwise test results). We also fail to reject a joint test of equality of the estimated coefficients $\left(\chi^{2}(3)=2.23, p=0.526\right)$. The next part of Hypothesis 2 stated that the estimated slope on the $\mathcal{S}$ treatment is smaller than all other estimated slope coefficients. However, the slope coefficients in the $\mathcal{S}$ and $\mathcal{T}$ treatments are virtually the same and not statistically significantly different $\left(\chi^{2}(1)=0.08, p=0.781\right)$. When comparing $\mathcal{A}$ and $\mathcal{S}$, the slope coefficients are nominally different but statistically not

\footnotetext{
${ }^{14}$ We also include in the Appendix tests of the point predictions of the model.
} 


\begin{tabular}{llllll}
\hline & $\mathcal{T}$ & $\mathcal{W}$ & $\mathcal{S}$ & $\mathcal{A}$ & $\mathcal{N}$ \\
\hline Winning worker & 24.87 & 23.72 & 21.89 & 22.46 & 20.63 \\
& $(0.51)$ & $(0.37)$ & $(1.80)$ & $(0.61)$ & $(1.61)$ \\
Losing worker & 12.46 & 10.55 & 12.98 & 12.91 & 11.11 \\
& $(0.36)$ & $(0.56)$ & $(1.45)$ & $(0.55)$ & $(0.84)$ \\
N:3150 & & & & &
\end{tabular}

Session-level clustered SEs in parentheses

significantly different $\left(\chi^{2}(1)=0.98, p=0.322\right)$. We note that the estimated coefficients are very tightly bound, so this lack of statistical significance is unlikely to be from noise. In all other pairwise comparisons, the differences in estimated slope coefficients were highly significant $\left(\chi^{2}(1) \geq 9.06, p \leq 0.003\right)$. Furthermore a joint test of equality across all pairwise comparisons with $\mathcal{S}$ yielded a significant difference $\left(\chi^{2}(4)=21.21, p<0.001\right)$. The final comparative static prediction was that the slope of the bidding function in $\mathcal{W}$ was steeper than in other treatments. With the exception of the comparison with $\mathcal{B}\left(\chi^{2}(1)=2.60, p=0.107\right)$, all pairwise tests were significant $\left(\mathcal{A}=\mathcal{W}: \chi^{2}(1)=3.41, p=0.065 ; \quad \mathcal{T}=\mathcal{W}\right.$ : $\left.\chi^{2}(1)=6.30, p=0.012 ; \mathcal{N}=\mathcal{W}: \chi^{2}(1)=35.04, p<0.001\right)$; a joint test of equality was also highly significant $\left(\chi^{2}(4)=37.21, p<0.001\right)$.

We proceed with estimated intercept comparisons. The model predicts that the estimated bidding functions for $\mathcal{W}, \mathcal{B}$ and $\mathcal{T}$ have the same intercept. We reject that hypothesis $\left(\chi^{2}(2)=33.25, p<0.001\right)$. The model also predicts that the $\mathcal{S}$ will have the highest intercept; while the estimated intercept for $\mathcal{S}$ is significantly larger than $\mathcal{B}\left(\chi^{2}(1)=33.23, p<0.001\right), \mathcal{T}\left(\chi^{2}(1)=9.00, p=0.003\right)$ and $\mathcal{W}\left(\chi^{2}(1)=10.21, p=0.001\right)$, it is not statistically significantly different to that of $\mathcal{N}\left(\chi^{2}(1)=0.27, p=0.600\right)$ or $\mathcal{A}\left(\chi^{2}(1)=0.57, p=0.452\right)$; a joint test of equality of intercepts was highly significant $\left(\chi^{2}(5)=96.10, p<0.001\right)$. The second highest intercept is predicted by the model to be that of $\mathcal{A}$; while the estimated coefficient in $\mathcal{A}$ is indeed significantly larger than that of $\mathcal{W}, \mathcal{B}$, and $\mathcal{T}$ (all comparisons, $\chi^{2}(1) \geq 13.42, p<0.001$ ), it is not significantly different to that of $\mathcal{N}\left(\chi^{2}(1)=1.41, p=0.235\right)$; a joint test of significance yielded a significant difference $\left(\chi^{2}(4)=74.92, p<0.001\right)$. Finally, the model predicts that the empirical bidding function in $\mathcal{N}$ will have a higher intercept than that $\mathcal{W}, \mathcal{B}$ and $\mathcal{T}$. We find significant differences in estimated intercepts in all pairwise comparisons $\left(\mathcal{W}: \chi^{2}(1)=4.12, p=0.042 ; \mathcal{B}: \chi^{2}(1)=17.04, p<0.001\right.$; $\left.\mathcal{T}: \chi^{2}(1)=4.52, p=0.034\right)$; a joint test of equality of intercepts was highly significant $\left(\chi^{2}(4)=67.96, p<0.001\right)$.

\subsubsection{Wages}

We now turn to the effect of different disclosure rules on wages. Our third hypothesis stated that workers that win the first-stage auction should receive a higher wage than workers that lose it. Table 4 summarizes the estimates of a regression of wage offer 


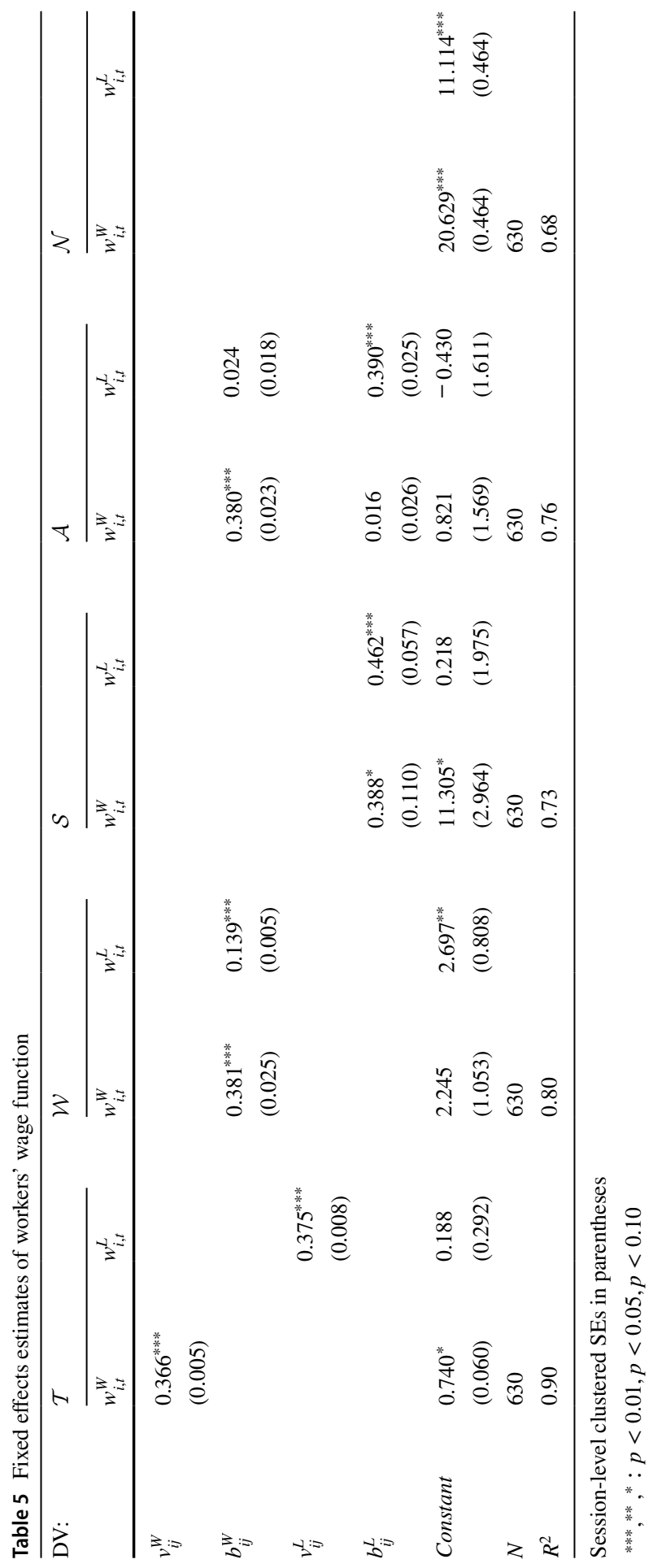


Table 6 Firm profits

\begin{tabular}{llllll}
\hline & $\mathcal{T}$ & $\mathcal{W}$ & $\mathcal{S}$ & $\mathcal{A}$ & $\mathcal{N}$ \\
\hline & $1.06^{* * *}$ & $2.44^{* * *}$ & 1.84 & $1.48^{*}$ & $3.67^{* * *}$ \\
& $(0.13)$ & $(0.18)$ & $(1.25)$ & $(0.80)$ & $(1.14)$ \\
$\mathrm{N}: 3150$ & & & & & \\
\hline
\end{tabular}

Session-level clustered SEs in parentheses.

***,**,* $: p<0.01, p<0.05, p<0.10$

in stage 2 on a series of treatment dummies interacted with a dummy for stage- 1 auction winner. As before, we present the directly estimated coefficients for ease of exposition. Table 11 displays regression estimates of the dummy coefficients.

Result 3: Workers who win the first-stage auction receive higher wages than workers who do not win the first-stage auction.

Support: Winning workers earn substantially higher wages than losers, as demonstrated by Table 4 . The difference is always statistically significant $\quad\left(\mathcal{T}: \quad \chi^{2}(1)=209.04, p<0.001 ; \quad \mathcal{W}: \quad \chi^{2}(1)=204.85, p<0.001\right.$; $\mathcal{S}: \quad \chi^{2}(1)=55.76, p<0.001 ; \quad \mathcal{A}: \quad \chi^{2}(1)=18776.37, p<0.001 ; \quad \mathcal{N}:$ $\left.\chi^{2}(1)=148.48, p<0.001\right)$.

We now turn to Hypothesis 4, which pertained to the shape of the wage function for the two workers. Table 5 summarizes the results from estimations of the wage equations for the winning worker and losing worker in each treatment as a function of the relevant stage-one auction variables.

Result 4: (a) The estimated wage functions for the winning worker in $\mathcal{T}$ and $\mathcal{A}$ have similar slopes to those of the losing workers' but higher intercepts. (b) In disclosure rule $\mathcal{W}$, the winning worker's wage is more responsive than the losing worker's wage to the winning worker's bid. (c) In disclosure rule $\mathcal{S}$ the losing worker's wage is not significantly more responsive than the winning worker's wage to the losing worker's bid. (d) Average wages are higher for the winning worker than for the losing worker in the $\mathcal{N}$ treatment.

Support: (a) In the $\mathcal{T}$ treatment, the estimated intercept for the winning worker's wage function is larger but not significantly different than that of the losing worker's $(F(1,2)=5.53, p=0.143)$; the slope coefficient of the losing worker's wage function is marginally significantly different to the winning worker's $(F(1,2)=10.46, p=0.084)$. A joint test of equality of slope and intercept is only marginally significant $(F(1,2)=10.94, p=0.084)$. In the $\mathcal{A}$ treatment, the comparisons of interest is on the coefficient on the winning worker's own bid versus the coefficient on the losing workers' bid, as well as both workers' intercept coefficients. The former test yields a non statistically significant difference $(F(1,2)=0.09, p=0.794)$, but the latter yields a statistically significant difference $(F(1,2)=29.15, p=0.033)$. (b) In the $\mathcal{W}$ treatment, the estimated slope coefficients are statistically significantly different $(F(1,2)=104.56, p=0.009)$. (c) In the $\mathcal{S}$ treatment, the estimated slope coefficients are not statistically significantly different $(F(1,2)=1.63, p=0.330)$. (d) In the $\mathcal{N}$, we observe a significant difference in average wages $\left(\chi^{2}(1)=105.26, p=0.009\right)$. 


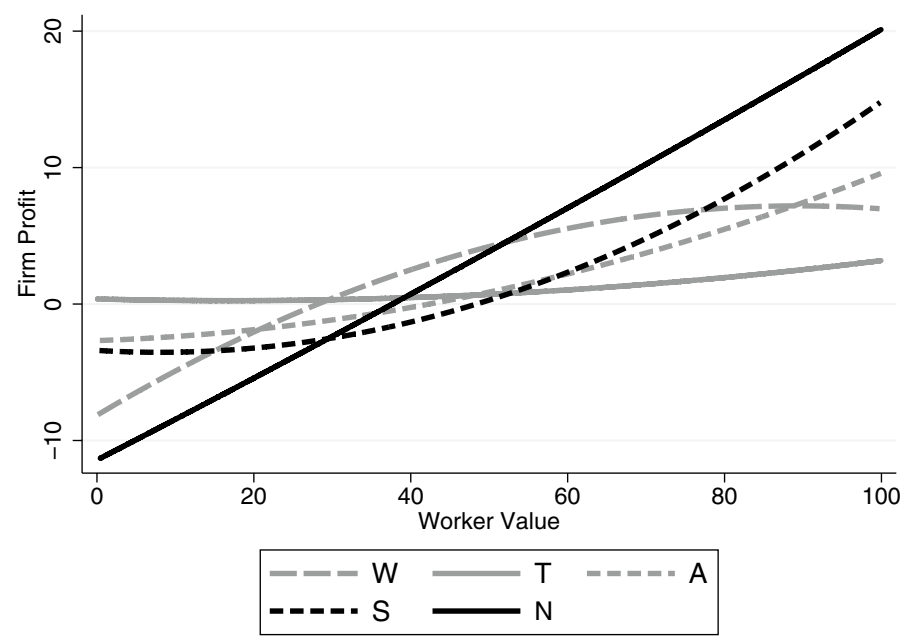

Fig. 2 Firm profits as a function of workers' private values

We conclude this subsection with the fifth hypothesis, which stated that firms should make zero profits in all disclosure conditions. Table 6 summarizes estimated average profits across all relevant conditions from a GLS regression of firm profits on treatment dummies.

Result 5: In all treatments except $\mathcal{S}$, firms make positive profits. In $\mathcal{S}$, firms make zero profits.

Support: We find positive estimates of profits across all treatments. However, they are only significant in the case of $\mathcal{T}\left(\chi^{2}(1)=63.00, p<0.001\right)$, $\mathcal{W} \quad\left(\chi^{2}(1)=177.30, p<0.001\right) \quad \mathcal{A} \quad\left(\chi^{2}(1)=3.47, p=0.062\right)$ and $\mathcal{N}$ $\left(\chi^{2}(1)=10.39, p=0.001\right)$; in the case of $\mathcal{S}$, the estimated profit was not significantly different than zero $\left(\chi^{2}(1)=2.18, p=0.140\right)$.

One interesting feature of our data is that firms are not making zero profits, as theory predicts. Empirical data on Bertrand duopolies (Dufwenberg and Gneezy 2000; Fonseca and Normann 2012) suggests that subjects may not reach the Bertrand-Nash equilibrium, particularly when the number of players is low, as is the case in our paper. In the case of our specific experiment, there is a potential additional reason why, on average, profits end up being positive: firms may form the wrong beliefs about workers' private values. That explanation should be valid if profits are significantly higher in the limited disclosure treatments than in $\mathcal{T}$. In fact, we see mixed evidence in favor of that explanation. There is no statistically significant difference in profits between $\mathcal{T}$ and $\mathcal{S}\left(\chi^{2}(1)=0.39, p=0.534\right)$, or $\mathcal{A}\left(\chi^{2}(1)=0.28, p=0.599\right)$ but, firms make higher profits on average in $\mathcal{W}$ $\left(\chi^{2}(1)=37.12, p<0.001\right)$. and $\mathcal{N}\left(\chi^{2}(1)=5.18, p=0.023\right)$. 


\subsection{The role of interim beliefs}

The above results apply when we average over the valuations, so that it is worth considering whether matters change for particular valuations. Figure 2 displays estimates of firm profits conditional on the private value of the hired worker and its square value for each of our treatments where there was an aftermarket. In $\mathcal{T}$, firm profits are consistently close to zero, as predicted. In contrast, in the limited disclosure treatments, firms consistently make losses on workers whose private values were low, but make reasonably large profits when private values are high. The most extreme case is the $\mathcal{N}$ treatment, while the other treatments lie somewhere in between. This suggests that firms were also unable to correctly infer worker types from their bidding behavior in stage 1 at either end of the distribution of private values.

The only way to be sure incorrect beliefs were at the heart of incorrect bidding for particular types, as opposed to alternative explanations such as decision error, we needed explicit data on beliefs. However, we did not include belief elicitation in our original design, as we felt it would be detrimental to decision quality in an already complex environment.

In order to understand to what extent bidding behavior in the first-stage auction lead to correct beliefs about valuations, we conducted an additional experiment. The purpose of this experiment is to see to what extent firms offer or accept wages using correct information. We recruited a separate sample of subjects from the same subject pool as the main treatments. Upon arrival to the laboratory, subjects sat in individual computer booths, and verbal communication was not allowed at any time. Subjects were told they were taking part in an individual choice experiment. The instructions told subjects they would observe a sequence of bids placed by subjects in the firststage of the earlier $\mathcal{A}$ treatment. Their task was to guess the private values of each of the two workers in each period. The instructions included a copy of the instruction set used in the $\mathcal{A}$ treatment. ${ }^{15}$ See the Appendix for the instructions for this treatment.

To make the guesses incentive-compatible, we employed a quadratic scoring rule of the form:

$$
10,000-(\text { true value }- \text { predicted value })^{2}
$$

Quadratic scoring rules are incentive-compatible if subjects are risk-neutral, expected utility maximizers (Offerman et al. 2009). Those assumptions are the ones made by our theoretical model, hence this belief elicitation method is suitable to our set up. We conducted two sessions with 18 participants in each session. This means that two subjects in the belief elicitation sessions observed the same sequence of bids - this allowed us to test for the consistency of guesses. Indeed, beliefs were very consistent: the average Spearman correlation for pairs of "guessing participants" was 0.84 , with only two cases having a Spearman correlation below 0.75 . We are therefore confident that the elicited beliefs are reliable measures of the predicted workers' private values.

$\overline{15}$ Of course, these subjects did not observe any outcomes from the second stage. 
Table 7 Estimates of firm beliefs as a function of observed bids

\begin{tabular}{|c|c|c|c|c|c|c|}
\hline & \multicolumn{2}{|c|}{ Winning worker } & \multicolumn{2}{|c|}{ Losing Worker } & \multicolumn{2}{|l|}{ Pooled } \\
\hline & (W1) & (W2) & (L1) & (L2) & (P1) & $(\mathrm{P} 2)$ \\
\hline \multirow[t]{2}{*}{$b_{i j} \times \mathcal{I}\left(b_{i j}<40\right)$} & $0.18^{* * *}$ & & -0.06 & & 0.02 & \\
\hline & $(0.06)$ & & $(0.03)$ & & $(0.02)$ & \\
\hline \multirow[t]{2}{*}{$\mathcal{I}\left(b_{i j}<40\right)$} & $-7.85^{* * *}$ & & 0.67 & & $-3.03^{* * *}$ & \\
\hline & $(1.76)$ & & $(0.74)$ & & $(0.98)$ & \\
\hline \multirow{2}{*}{$b_{i j} \times \mathcal{I}\left(b_{i j}>90\right)$} & $-4.67^{* *}$ & & & & $-4.71^{* *}$ & \\
\hline & $(2.12)$ & & & & $(2.11)$ & \\
\hline \multirow[t]{2}{*}{$\mathcal{I}\left(b_{i j}>90\right)$} & $430.83^{* *}$ & & & & 434.84 & \\
\hline & (196.47) & & & & (196.18) & \\
\hline \multirow[t]{2}{*}{$b_{i j}$} & $0.93^{* * *}$ & $0.97^{* * *}$ & $0.99^{* * *}$ & $0.99^{* * *}$ & $0.98^{* * *}$ & $1.02^{* * *}$ \\
\hline & $(0.02)$ & $(0.02)$ & $(0.02)$ & $(0.02)$ & $(0.02)$ & $(0.01)$ \\
\hline \multirow[t]{2}{*}{ Constant } & $8.02^{* * *}$ & $5.40^{* * *}$ & 0.82 & 0.81 & $4.01^{* * *}$ & $1.03^{* *}$ \\
\hline & $(1.40)$ & $(0.99)$ & $(0.59)$ & $(0.54)$ & $(1.05)$ & $(0.50)$ \\
\hline $\mathrm{N}$ & 1260 & & 1260 & & 2520 & \\
\hline$R^{2}$ & 0.84 & 0.83 & 0.88 & 0.83 & 0.90 & 0.90 \\
\hline
\end{tabular}

$* * * p<0.01$. Individual-level clustered standard errors in parentheses

Note that the theoretical bidding function here is given by $\frac{1}{2} x_{i}+40$, which implies that we should not observe bids below 40 or above 90 . Any such bids are off-theequilibrium path behavior and, as required by the equilibrium under consideration, any bids below 40 should lead to beliefs that put probability one on type zero while any beliefs above 90 should lead to beliefs that put probability one on type 100. In our treatment, $19 \%$ (68\%) of bids by the winning (losing) worker were below 40, but only $1 \%(0 \%)$ of bids by the winning (losing) worker were above 90 . Table 7 presents estimation results of elicited beliefs as a function of observed bids by the winning and losing worker in the first-stage auction from the $\mathcal{A}$ sessions. To capture the piecewise linear nature of the predicted belief function, that is

$$
\begin{array}{lll}
0 & \text { if } & b<40 \\
2 b-80 & \text { if } & 40 \leq b \leq 90 \\
100 & \text { if } & b>90
\end{array}
$$

we regressed the belief about worker value on $b_{i j}$ with dummies for the case when $b_{i j}>90$ and $b_{i j}<40$, and their interactions with $b_{i j}$. In addition, we ran a linear specification. We consider three samples: the beliefs on the winning worker value, the losing worker, and the pooled data (since the belief function should be the same for both workers).

It is important to note that the linear function performs equally well as the piecewise model, as can be noted by the $R^{2}$ for both models (regardless of whether we look at the winning worker, losing worker or the pooled data). Figure 3 (left) plots the theoretical belief function for both winning and losing workers in the $\mathcal{A}$ treatment; it 

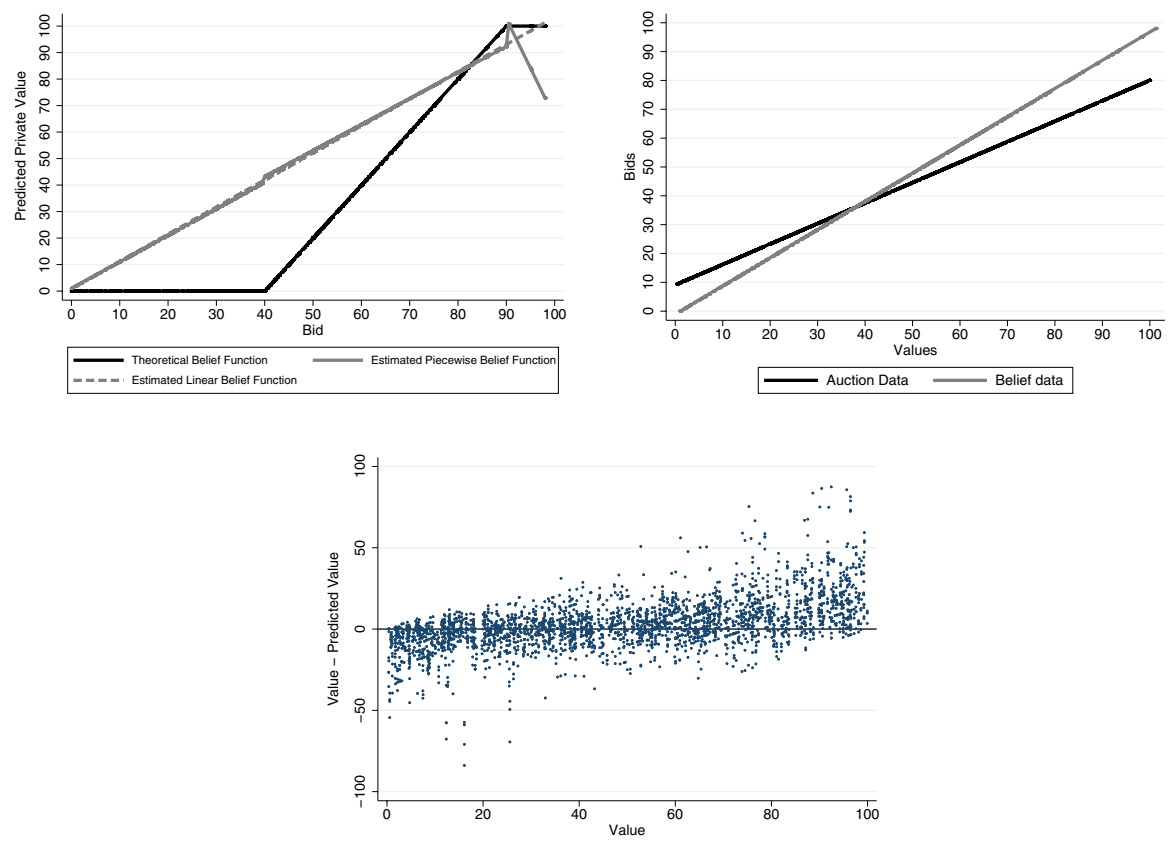

Fig. 3 Left: theoretical (black) vs. estimated (grey/blue) belief functions. Right: estimated bidding function from auction (black) and inverted belief function (grey). Bottom: prediction error from elicited beliefs

also plots the two estimated belief functions: the piecewise linear model that corresponds to the theoretical model and a simple linear specification, as per Table 7.

Two aspects are noteworthy: firstly, both empirical belief functions are practically indistinguishable, which suggests that the more parsimonious specification is the better model for the belief data. Secondly, both empirical belief functions differ substantially from the theoretical belief function for observed bids below 40off-equilibrium behavior. This suggests that firms in the main experiment expected workers with low private values to overbid less than suggested by the theory (which, if anticipated by workers, then removed their strategic incentive to do so).

This leads us to ask: were firms able to predict bidding behavior well? Figure 3 (right) plots the inverted belief function (linear specification) against the empirical bidding function from workers in the $\mathcal{A}$ treatment. The empirical bidding function (blue) is slightly flatter than the inverted belief function and it has a higher intercept. In the discussion of Result 5 at the beginning of this subsection, we highlighted how firms choose wages that produce profits closer to theoretical predictions for intermediate valuations and farther from those predictions for extreme valuations. In that context we suggested that it may be difficult for the aftermarket to predict bidding behavior in these circumstances. Figure 3 (right) confirms that suggestion: firms may have underestimated both the degree to which workers bid in excess of their private value when the draw was low, as well as the extent to which they bid below their private value when their draw was high. 
Figure 3 (bottom) further confirms this conjecture; it plots the prediction error for each belief elicitation data point against the true private value. Most predictions are quite accurate: the median absolute error in predicted values was $6.75 \mathrm{ECU}$, and $75 \%$ of observations had an absolute error lower than 13.2 ECU. However, the most extreme cases of prediction error are at the extremes of the domain of private values. We verify this by running a regression of the absolute error in prediction on private value and private value squared. We obtain a constant coefficient of 10.86 (robust s.e. 0.63), a coefficient of -0.26 (robust s.e. 0.03 ) on private value and a coefficient of 0.004 (robust s.e. 0.0004$)$ on the square of private value $\left(N=2520, R^{2}=0.16\right)$. Thus, the highest errors in prediction come from the extremes of the private value distribution.

\subsection{Discussion}

The results of the experiment partly confirm the theoretical predictions of the model. In particular, comparing the bidding behavior in the $\mathcal{B}$ and $\mathcal{T}$ treatments with the other treatments suggests that workers realize that they are participating in a signaling game and (over)bid accordingly. In particular, the bidding behavior of workers in the $\mathcal{A}, \mathcal{W}$ and $\mathcal{N}$ treatments suggests that individuals grasped the basic incentives. When queried in a non-incentivized, open ended questionnaire about how they made their bidding decisions, $48 \%$ of workers reported bidding higher than their private value when the realization was 'low', and bidding below their private value when the realization was 'high'. Just under $50 \%$ of workers in these treatments explained their bidding behavior as a function of second-stage outcomes, either as responding to expected wage offers, or even explaining their behavior as signaling a particular type. However, subjects also stated reducing their overbidding in periods where they drew a higher private value. This is a plausible explanation as to why the treatment effects are weaker than what theory would predict. ${ }^{16}$

In the $\mathcal{S}$ treatment, bidding behavior was not what we would expect from the theory. This is not entirely surprising, as this is certainly the most difficult disclosure rule to think about, for two main reasons. The first is that the disclosure rule itself may be difficult to interpret since we have a first-price auction, but only the losers' bid is disclosed. The second reason is that in the symmetric and monotone equilibrium, workers with low valuations face a trade-off between bidding low given their valuation of the object and bidding high for signaling purposes (as their valuation

\footnotetext{
16 This post-experimental questionnaire response is a case in point: "Whether I made a bid higher or lower than the value of the prize depended on how high the value of the prize was. If the value was high then I was more likely to bid lower than the prize value, as I was still likely to win the auction, and I decided that the underestimate of the prize would give me a greater profit than the higher offer the firms would make me in the result of a higher bid, as they want to keep their offers as low as possible in order to maximise their own profit. If the prize value was low however, I tended to bid more than the prize value, as this would entice the firms to give me a higher offer, which would hopefully offset the loss I'd made at the auction (this was a mistake when the prize value was exceptionally low however, as the offers from the firms were also extremely low). If the price value was in the middle range, I tended to still bid lower than the prize value, as I decided the risk of losing the auction was still worth taking for a higher profit from the auction."
} 
is likely to be revealed if they do not overbid), while workers with high valuations face the reverse trade-off. In other words, in the $\mathcal{S}$ treatment workers face a trade-off between their standard auction incentives and their signaling incentives, and equilibrium bidding behavior requires them to finely balance these opposing incentives. This does not happen with the other disclosure rules where the incentives to overbid are (weakly) monotonic in the valuations: in the $\mathcal{A}$ and $\mathcal{N}$ treatments, these incentives are the same regardless of the valuation whereas in the $\mathcal{W}$ treatment, the higher the valuation, the higher the incentive to overbid. All of this implies that bidding in the $\mathcal{S}$ treatment is significantly more complex than in the other treatments. As such, it should not be too surprising that even if the incentives are correctly understood, their implementation in the bidding process may fail.

Regarding wage-setting in the second stage, the model's predictions are also broadly confirmed, with $\mathcal{S}$ data again diverging the most from theoretical predictions. It is particularly interesting to note that bidders seem to understand that if a worker's bid is disclosed, that should have a greater impact on this worker's wage than on the wage of a worker whose bid is not disclosed. Over 53\% of firm subjects stated in the post-experimental questionnaire that they had discriminated between the winning and the losing worker in their wage offers across all treatments. In the $\mathcal{W}$ and $\mathcal{S}$ that proportion was $92 \%$ and $67 \%$, respectively. Notably, very few firm subjects expressed concerns about over- or under-bidding by workers ( $8 \%$ and $12 \%$ ) respectively - most observations of both types of concerns came from firms in the $\mathcal{S}$ treatment, which suggests this was the treatment in which behavior was most noisy. A substantial number of firm subjects reported applying a differential mark-down based on the observed bids (e.g. "As a Firm I decided to bid below $40 \%$ of the workers bid price if it was winner. If it was a loser then I bid at $20 \%$ or less. My main aim was to offer the lowest price possible for a worker, but still trying to beat the other firm. I had base my bids off past bids other firms made.")

Risk aversion has been often raised as a possible explanation for over-bidding in private value auctions in the lab (c.f. Cox et al. 1985, 1988; Smith and Walker 1993; Goeree and Holt 2002). We feel that this is an implausible reason for deviations from our theoretical benchmark which explicitly assumes risk neutrality. The main basis for our position is theoretical in nature. Arrow (1971) and Rabin (2000) show that risk aversion as postulated by expected utility theory must imply risk neutral behavior for small stakes - such as those typically used in laboratory experiments. As such, we feel that the traditional definition of risk aversion, which relies on the concavity of one's utility function, is not a good candidate for the deviations.

We conclude our discussion by revisiting the data on beliefs. The estimated belief function was qualitatively similar to predictions for the range of bids one would expect to observe in equilibrium, but it differed dramatically for ranges of bids that are outof-equilibrium. In particular, subjects seemed to discount the incentive to overbid by low types: recall that in theory such incentive should be such that no subject would bid below 40 in equilibrium. This may have removed the incentive by workers to overbid to the extent predicted by theory when drawing a low private value. These results also confirm that the explanation for excess profits in our treatments may be partly attributable to firms not being able to correctly guess valuations, when they are extreme, from bidding behavior. 


\section{Conclusions}

This paper is the first to present an experimental analysis of signaling through auctions and does so in a context where bidders' valuations in a first-stage auction are positively correlated with the expected returns in an aftermarket. To do so, we adopt the framework in Giovannoni and Makris (2014) which allows for easily testable implications. We interpret the aftermarket as a labor market where the first-stage bidders (workers) have a productivity that is a linear function of their first-stage valuations. We model the labor aftermarket in such a way that in equilibrium workers take all the surplus (as expected by firms) and equilibrium wages are therefore equal to what the firms believe to be their expected productivity. The theory predicts overbidding in the firststage auction under limited disclosure and, more interestingly, that different disclosure rules about what is known about bidding at the end of the first-stage auction influence bidding in the first-stage auction and wages in the second-stage auction. We test the theoretical predictions in an experiment, focusing on differences across disclosure rules. The results show that bidders understand the possibility of signaling their productivity through their bids and, further, that they also understand some of the qualitative differences in the signaling opportunities that arise from the various disclosure rules. Several predictions about wages in the aftermarket are also confirmed. However, our results also show that bidder behavior differs sufficiently from theoretical predictions to invalidate the predicted effect of different disclosure rules on revenue and firm profits. In particular, there is not as much overbidding for low valuation types as one would predict, although our belief elicitation analysis also shows that this behavior is to some degree (but not completely) anticipated from firms. From a revenue efficiency perspective, theory predicted that disclosing the losing bid would generate the highest level of revenue alongside the treatment where both bids are revealed. In contrast, our results suggest that revealing the winning bid can be, for the seller, equally beneficial to revealing all the bids and strictly better than revealing the losing bid. Our data suggests that the losing-bid disclosure rule should be used in practice with caution. It is the most cognitive demanding environment as argued earlier, and it leads to less consistent behavior relative to theoretical benchmarks.

Acknowledgements We would like to thank Nick Feltovich, Ken Binmore, Christos Ioannou, Leeat Yariv as well as participants at the 2016 Game Theory World Congress for their helpful comments and suggestions. Financial support from the British Academy through the grant SG113004, as well as from the University of Bristol is gratefully acknowledged. The usual disclaimer applies.

Open Access This article is licensed under a Creative Commons Attribution 4.0 International License, which permits use, sharing, adaptation, distribution and reproduction in any medium or format, as long as you give appropriate credit to the original author(s) and the source, provide a link to the Creative Commons licence, and indicate if changes were made. The images or other third party material in this article are included in the article's Creative Commons licence, unless indicated otherwise in a credit line to the material. If material is not included in the article's Creative Commons licence and your intended use is not permitted by statutory regulation or exceeds the permitted use, you will need to obtain permission directly from the copyright holder. To view a copy of this licence, visit http://creativecommons.org/licen ses/by/4.0/. 


\section{Appendix}

\section{A.1 Equilibria}

In this part of the appendix, we provide a more detailed treatment of the theory discussed in Sect. 2. Following Giovannoni and Makris (2014), we make the following restriction on off-the-equilibrium-path beliefs, which we will apply to both aftermarket settings: ${ }^{17}$

Assumption $\mathrm{A}$ We assume that in any such equilibrium, any bid $b_{i}$ lower than $\beta^{\phi}(0)$ is believed to come from valuation $x_{i}=0$ and any bid $b_{i}$ higher than $\beta^{\phi}(100)$ is believed to come from valuation $x_{i}=100$. Further, if there is a bid $b_{i}$ and a valuation $\hat{x}$ such that $b_{i} \in\left(\lim _{x_{i} \rightarrow \hat{x}^{-}} \beta^{\phi}\left(x_{i}\right), \lim _{x_{i} \rightarrow \hat{x}^{+}} \beta^{\phi}\left(x_{i}\right)\right)$ then $b_{i}$ is believed to come from valuation $x_{i}=\hat{x}$.

Proposition in the main text allows us to rewrite the expected utility for worker $i$ as

$$
E U_{i}\left(\mathbf{b}, x_{i}, \phi\right)=\left[\operatorname{Pr}\left(b_{i}>b_{j}\right)+\frac{1}{2} \operatorname{Pr}\left(b_{i}=b_{j}\right)\right]\left(x_{i}-b_{i}\right)+\alpha E\left(X_{i} \mid \mathcal{I}^{\phi}\right)
$$

Assumption A, in turn, allows us to associate to each vector of bids $\mathbf{b}$ a corresponding vector $\mathbf{z}$ of valuations, which we refer to as announcements. ${ }^{18}$ For convenience, we will define the functions

$$
\begin{gathered}
v_{\omega}^{\phi}\left(x_{j}, z_{i}\right)=E\left(X_{i} \mid \mathcal{I}^{\phi}, \omega=i\right) \\
v_{-\omega}^{\phi}\left(x_{j}, z_{i}\right)=E\left(X_{i} \mid \mathcal{I}^{\phi},-\omega=i\right)
\end{gathered}
$$

as the firms' expectations about $i$ 's productivity at the end of the first-stage auction, given the disclosure rule and the fact that $i$ won or lost the auction. This notation emphasizes that these beliefs may be, in equilibrium, a function of the other bidder's valuation and $i$ 's own announcement. ${ }^{19}$ Then, following an announcement $z_{i}$, the expected payoff for bidder $i$ as a function of $z_{i}$ and valuation $x_{i}$ is

\footnotetext{
${ }^{17}$ See Giovannoni and Makris (2014) for a discussion of assumption $\mathrm{A}$ and the focus on these equilibria.

18 That is, with $z_{i}$ such that $\left(\beta^{\phi}\right)^{-1}\left(b_{i}\right)=z_{i}$ if $b_{i} \in \beta^{\phi}\left(X_{i}\right), z_{i}=100$ if $b_{i}>\beta^{\phi}(100)$ and $z_{i}=\hat{x}$ if $b_{i} \in\left(\lim _{x \rightarrow \hat{x}^{-}} \beta^{\phi}(x), \lim _{x \rightarrow \hat{x}^{+}} \beta^{\phi}(x)\right)$.

19 For example, if $\phi=\mathcal{A}$ then
}

whereas if if $\phi=\mathcal{W}$ then

$$
v_{\omega}^{\mathcal{A}}\left(x_{j}, z_{i}\right)=v_{-\omega}^{\mathcal{A}}\left(x_{j}, z_{i}\right)=z_{i}
$$

$$
\begin{aligned}
v_{\omega}^{\mathcal{W}}\left(x_{j}, z_{i}\right) & =z_{i} \\
v_{-\omega}^{\mathcal{W}}\left(x_{j}, z_{i}\right) & =E\left(X_{i} \mid X_{i}<x_{j}\right)
\end{aligned}
$$

The others follows analogously. 


$$
E U_{i}\left(z_{i}, x_{i}, \phi\right)=\frac{1}{100}\left[\int_{0}^{z_{i}}\left(x_{i}+\alpha v_{\omega}^{\phi}\left(X_{j}, z_{i}\right)-\beta^{\phi}\left(z_{i}\right)\right) d X_{j}+\int_{z_{i}}^{100} \alpha v_{-\omega}^{\phi}\left(X_{j}, z_{i}\right) d X_{j}\right]
$$

where we emphasize that this is an expectation with respect to $j$ 's valuation, conditional on equilibrium play from her. We define an effective valuation as

$$
\begin{aligned}
\psi^{\phi}\left(x_{i}\right)= & x_{i}+\alpha v_{\omega}^{\phi}\left(x_{i}, x_{i}\right)-\alpha v_{-\omega}^{\phi}\left(x_{i}, x_{i}\right) \\
& +\alpha\left[\int_{0}^{x_{i}}\left(\left.\frac{\partial v_{\omega}^{\phi}\left(X_{j}, z_{i}\right)}{\partial z_{i}}\right|_{z_{i}=x_{i}}\right) d X_{j}+\int_{x_{i}}^{100}\left(\left.\frac{\partial v_{-\omega}^{\phi}\left(X_{j}, z_{i}\right)}{\partial z_{i}}\right|_{z_{i}=x_{i}}\right) d X_{j}\right]
\end{aligned}
$$

We call these effective valuations because they capture all that is at stake for individual $i$ in the first-stage auction (assuming equilibrium play in the second stage). Specifically, we have the direct utility from winning the auction $x_{i}$, but also the reputational returns that $i$ can expect in the second-stage auction as a function of her valuation. The component $\alpha v_{\omega}^{\phi}-\alpha v_{-\omega}^{\phi}$ captures the net reputational gain to the bidder from winning the auction, while the remaining term in the square brackets captures the additional reputational net gain from marginally increasing the announcement. This definition allows us to state, following on from Giovannoni and Makris (2014), the following proposition:

Proposition A Given assumption A, equilibrium bidding functions $\beta^{\phi}$ of the firstprice sealed-bid auction are given by ${ }^{20}$

$$
\beta^{\phi}\left(x_{i}\right)=\frac{1}{x_{i}} \int_{0}^{x_{i}} \psi^{\phi}(s) d s, x_{i} \in[0,100]
$$

Proof Define

$$
\Psi^{\phi}\left(x_{i}, x_{j}, z_{i}\right)=x_{i}+\alpha v_{\omega}^{\phi}\left(x_{j}, z_{i}\right)-\alpha v_{-\omega}^{\phi}\left(x_{j}, z_{i}\right)
$$

and note that

$$
E U_{i}\left(x_{i}, z_{i}, \phi\right) \equiv \frac{1}{100}\left[\int_{0}^{z_{i}}\left[\Psi^{\phi}\left(x_{i}, X_{j}, z_{i}\right)-\beta\left(z_{i}\right)\right] d X_{j}+\int_{0}^{100} \alpha v_{-\omega}^{\phi}\left(X_{j}, z_{i}\right) d X_{j}\right]
$$

is the expected utility of valuation $x_{i}$ from bidding $\beta\left(z_{i}\right)$. Suppose now that a symmetric and strictly increasing equilibrium $\beta$ exists. Note then that in a such an equilibrium

$$
\frac{1}{100}\left[\int_{0}^{\beta^{-1}\left(b_{i}\right)}\left[\Psi^{\phi}\left(x_{i}, X_{j}, \beta^{-1}\left(b_{i}\right)\right)-b_{i}\right] d X_{j}+\int_{0}^{100} \alpha v_{-\omega}^{\phi}\left(X_{j}, \beta^{-1}\left(b_{i}\right)\right) d X_{j}\right]
$$

\footnotetext{
${ }^{20}$ Given that $N=2$ and that we have a uniform distribution, the bidding function is well-defined at $x_{i}=0$.
} 
is the expected profit of bidder with valuation $x_{i}$ from bidding $b_{i} \geq 0$,with, by assumption $\mathrm{A}, \beta^{-1}\left(b_{i}\right) \equiv 0$ if $b_{i}<\beta^{-1}(0), \beta^{-1}\left(b_{i}\right) \equiv 100$ if $b_{i} \geq \beta^{-1}(100)$,and $\beta^{-1}\left(b_{i}\right) \equiv \hat{x}$ if $b_{i} \in\left(\lim _{x_{i} \rightarrow \hat{x}^{-}} \beta^{-1}\left(x_{i}\right), \lim _{x_{i} \rightarrow \hat{x}^{+}} \beta^{-1}\left(x_{i}\right)\right)$. Moreover, $\beta$ being strictly increasing, is almost everywhere differentiable. The first-order condition (FOC) for a maximum of the expected profit of bidder with valuation $x_{i}$ is (except in points of non-differentiability of $\beta($.$) )$

$$
\begin{aligned}
\Psi^{\phi} & \left(x_{i}, \beta^{-1}\left(b_{i}\right), \beta^{-1}\left(b_{i}\right)\right)-b_{i} \\
& +\alpha \int_{0}^{\beta^{-1}\left(b_{i}\right)} \frac{\partial}{\partial z_{i}} v_{\omega}^{\phi}\left(X_{j}, \beta^{-1}\left(b_{i}\right)\right) d X_{j}+\alpha \int_{\beta^{-1}\left(b_{i}\right)}^{100} \frac{\partial}{\partial z_{i}} v_{-\omega}^{\phi}\left(X_{j}, \beta^{-1}\left(b_{i}\right)\right) d X_{j} \\
& =\beta^{-1}\left(b_{i}\right) \beta^{\prime}\left(\beta^{-1}\left(b_{i}\right)\right)
\end{aligned}
$$

So, if $\beta$ is a symmetric and strictly increasing equilibrium, then it must be that $b_{i}=\beta\left(x_{i}\right)$, with $\beta\left(x_{i}\right)>0$ for any $x_{i}>0$, and hence

$$
\Psi^{\phi}\left(x_{i}, x_{i}, x_{i}\right)-\beta\left(x_{i}\right)+\alpha \int_{0}^{x_{i}} \frac{\partial}{\partial z_{i}} v_{\omega}^{\phi}\left(X_{j}, x_{i}\right) d X_{j}+\alpha \int_{x_{i}}^{100} \frac{\partial}{\partial z} v_{-\omega}^{\phi}\left(X_{j}, x_{i}\right) d X_{j}=\beta^{\prime}\left(x_{i}\right) x_{i}
$$

almost everywhere in $x \in(0,100]$. One can easily see that if $\beta$ is a symmetric and strictly increasing equilibrium, then it must be continuous: if $\hat{x}$ was a jump point then bidding $\lim _{x \rightarrow \hat{x}^{-}} \beta(x)$ is preferred to bidding $\lim _{x \rightarrow \hat{x}^{+}} \beta(x)$ by bidder of valuation $\hat{x}$ (resp. $\hat{x}+\varepsilon$, where $\varepsilon$ is arbitrarily small) when $\lim _{x \rightarrow \hat{x}^{+}} \beta(x)=\beta(\hat{x})$ (resp. when $\left.\lim _{x \rightarrow \hat{x}^{-}} \beta(x)=\beta(\hat{x})\right)$; such deviation does not have an effect on the auction's outcome and the reputational return, but leads to lower price upon winning. Note also that in any symmetric and strictly increasing equilibrium, $\beta(0) x 0=0$. Continuity of $\beta$, and hence $\beta\left(x_{i}\right) x_{i}$, implies, therefore, that the differential equation

$$
\begin{aligned}
& \Psi^{\phi}\left(x_{i}, x_{i}, x_{i}\right)+\alpha \int_{0}^{x_{i}} \frac{\partial}{\partial z_{i}} v_{\omega}^{\phi}\left(X_{j}, x_{i}\right) d X_{j} \\
& \quad+\alpha \int_{x_{i}}^{100} \frac{\partial}{\partial z} v_{-\omega}^{\phi}\left(X_{j}, x_{i}\right) d X_{j}=\frac{d\left[\beta\left(x_{i}\right) x_{i}\right]}{d x_{i}}, x_{i} \in(0,100]
\end{aligned}
$$

with the boundary condition $\beta(0) x 0=0$ has a unique solution, for any $x \in[0,100]$, to the proposed equilibrium:

$$
\begin{aligned}
\beta\left(x_{i}\right)= & \frac{1}{x_{i}} \int_{0}^{x_{i}}\left[\Psi^{\phi}(s, s, s)+\alpha \int_{0}^{s} \frac{\partial}{\partial z_{i}} v_{\omega}^{\phi}\left(X_{j}, s\right) d X_{j}+\alpha \int_{s}^{100} \frac{\partial}{\partial z} v_{-\omega}^{\phi}\left(X_{j}, s\right) d X_{j}\right] d s \\
= & \frac{1}{x_{i}} \int_{0}^{x_{i}}\left[s+\alpha v_{\omega}^{\phi}(s, s)-\alpha v_{-\omega}^{\phi}(s, s)+\alpha \int_{0}^{s} \frac{\partial}{\partial z_{i}} v_{\omega}^{\phi}\left(X_{j}, s\right) d X_{j}\right. \\
& \left.+\alpha \int_{s}^{100} \frac{\partial}{\partial z_{i}} v_{-\omega}^{\phi}\left(X_{j}, s\right) d X_{j}\right] d s=\frac{1}{x_{i}} \int_{0}^{x_{i}} \psi^{\phi}(s) d s
\end{aligned}
$$

It remains thus to show that $\beta\left(x_{i}\right)$ is indeed an equilibrium. To this end, note first that, given that competitors deploy $\beta\left(x_{i}\right)$, any bidder is indifferent over any bid weakly lower than $\beta(0)$. Also, any bidder strictly prefers $\beta(100)$ to any higher bid. We have that 


$$
\begin{aligned}
\frac{\partial E U_{i}\left(x_{i}, z_{i}, \phi\right)}{\partial z_{i}}= & \frac{1}{100}\left[\Psi^{\phi}\left(x_{i}, z_{i}, z_{i}\right)-\beta\left(z_{i}\right)-\frac{d \beta_{\phi}\left(z_{i}\right)}{d z_{i}} z_{i}\right. \\
& \left.+\alpha \int_{0}^{z_{i}} \frac{\partial}{\partial z_{i}} v_{\omega}^{\phi}\left(X_{j}, z_{i}\right) d X_{j}+\alpha \int_{z_{i}}^{100} \frac{\partial}{\partial z_{i}} v_{\omega}^{\phi}\left(X_{j}, z_{i}\right) d X_{j}\right]
\end{aligned}
$$

So,

$$
\frac{\partial E U_{i}\left(x_{i}, z_{i}, \phi\right)}{\partial z_{i}}-\frac{\partial E U_{i}\left(z_{i}, z_{i}, \phi\right)}{\partial z_{i}}=\frac{1}{100}\left[\Psi^{\phi}\left(x_{i}, z_{i}, z_{i}\right)-\Psi^{\phi}\left(z_{i}, z_{i}, z_{i}\right)\right] .
$$

Given that $\Psi^{\phi}\left(x_{i}, z_{i}, z_{i}\right)$ is strictly increasing in $x_{i}$, we have that if $z_{i}<x_{i}$ then $\frac{\partial E U_{i}\left(x_{i}, z_{i}, \phi\right)}{\partial z_{i}}>\frac{\partial E U_{i}\left(z_{i}, z_{i}, \phi\right)}{\partial z_{i}}$, and vice versa. That is, $\frac{\partial E U_{i}\left(x_{i}, z_{i}, \phi\right)}{\partial z_{i}}$ is strictly increasing in $x_{i}$. Note also that $\beta\left(z_{i}\right)$ satisfies $\frac{\partial E U_{i}\left(z_{i}, z_{i}, \phi\right)}{\partial z_{i}}=0$ for any $z_{i} \in(0,100]$. These, in turn, imply that for any $z_{i}$ and $x_{i}$ such that $0<z_{i}<x_{i} \leq 100$ we have $\frac{\partial E U_{i}\left(x_{i}, z_{i}, \phi\right)}{\partial z_{i}}>0$, while for any $z_{i}$ and $x_{i}$ such that $0 \leq x_{i}<z_{i} \leq 100$ we have $\frac{\partial E U_{i}\left(x_{i}, z_{i}, \phi\right)}{\partial z_{i}}<0$. Note also that for any $x_{i}>0$ bidding $\beta(0)$ is not optimal. To see this, note first that from the above we have that $\frac{\partial E U_{i}\left(x_{i}, z_{i}, \phi\right)}{\partial z_{i}} \geq 0$ for any $z_{i}=\varepsilon$ where $\varepsilon$ is arbitrarily small. So, it will be enough to show that $E U_{i}\left(x_{i}, 0, \phi\right) \leq \lim _{z_{i} \rightarrow 0^{+}} E U_{i}\left(x_{i}, z_{i}, \phi\right)$. This holds as an equality by continuity of $v_{-\omega}^{\phi}\left(x_{j}, z_{i}\right)$. Thus, $z_{i}=x_{i}$ is indeed indeed a global maximum of $E U_{i}\left(x_{i}, z_{i}, \phi\right)$, for any $x \in[0,100]$, given that competitors deploy $\beta$. Thus, $\beta$ is an equilibrium.

\section{A.2 Bidding and wage functions}

We calculate bidding and wage functions for all our treatments. Define

$$
\begin{aligned}
& M(x)=E\left[X_{i} \mid X_{i}>x\right]=\frac{1}{1-\frac{x}{100}} \int_{x}^{100} X_{i} \frac{1}{100} d X_{i}=\frac{1}{2}(x+100) \\
& \Lambda(x)=E\left[X_{i} \mid X_{i}<x\right]=\frac{1}{\frac{x}{100}} \int_{0}^{x} X_{i} \frac{1}{100} d X_{i}=\frac{1}{2} x
\end{aligned}
$$

then it is easy to see that ${ }^{21}$

$$
\begin{aligned}
& v_{\omega}^{\mathcal{T}}\left(x_{j}, z_{i}\right)=v_{-\omega}^{\mathcal{T}}\left(x_{j}, z_{i}\right)=v_{\omega}^{\mathcal{T}}\left(x_{j}, x_{i}\right)=v_{-\omega}^{\mathcal{T}}\left(x_{j}, x_{i}\right)=x_{i} \\
& v_{\omega}^{\mathcal{A}}\left(x_{j}, z_{i}\right)=z_{i} ; v_{-\omega}^{\mathcal{A}}\left(x_{j}, z_{i}\right)=z_{i} \\
& v_{\omega}^{\mathcal{W}}\left(x_{j}, z_{i}\right)=z_{i} ; v_{-\omega}^{\mathcal{W}}\left(x_{j}, z_{i}\right)=\frac{1}{2} x_{j} \\
& v_{\omega}^{\mathcal{S}}\left(x_{j}, z_{i}\right)=\frac{1}{2}\left(x_{j}+100\right) ; v_{-\omega}^{\mathcal{S}}\left(x_{j}, z_{i}\right)=z_{i} \\
& v_{\omega}^{\mathcal{N}}\left(x_{j}, z_{i}\right)=\frac{1}{100} \int_{0}^{100}\left(\frac{1}{2}(y+100)\right) d y=75 ; \\
& v_{-\omega}^{\mathcal{N}}\left(x_{j}, z_{i}\right)=\frac{1}{100} \int_{0}^{100}\left(\frac{1}{2} y\right) d y=25
\end{aligned}
$$

${ }^{21}$ The $\phi=\mathcal{B}$ case is the standard IPV case, so that we already know that for this case the effective valuation is the standard valuation $x_{i}$. 
which gives

$$
\begin{aligned}
\psi^{\mathcal{T}}\left(x_{i}\right) & =x_{i} \\
\psi^{\mathcal{A}}\left(x_{i}\right) & =x_{i}+100 \alpha \\
\psi^{\mathcal{W}}\left(x_{i}\right) & =x_{i}\left(\frac{3}{2} \alpha+1\right) \\
\psi^{\mathcal{S}}\left(x_{i}\right) & =x_{i}\left(1-\frac{3}{2} \alpha\right)+150 \alpha \\
\psi^{\mathcal{N}}\left(x_{i}\right) & =x_{i}+50 \alpha
\end{aligned}
$$

and this leads to the bidding functions presented in the main text. These and Proposition 1 imply (using the definition that $I\left(x_{i}, x_{j}\right)=1$ if $x_{i}>x_{j}$ and zero otherwise) that

$$
\begin{aligned}
w_{i}^{\mathcal{T}}\left(x_{i}, x_{j}\right) & =\alpha x_{i} \\
w_{i}^{\mathcal{A}}\left(x_{i}, x_{j}\right) & =\alpha x_{i} \\
w_{i}^{\mathcal{W}}\left(x_{i}, x_{j}\right) & =\alpha x_{i} I\left(x_{i}, x_{j}\right)+\frac{\alpha}{2} x_{j}\left(1-I\left(x_{i}, x_{j}\right)\right) \\
w_{i}^{\mathcal{S}}\left(x_{i}, x_{j}\right) & =\frac{\alpha}{2}\left(x_{j}+100\right) I\left(x_{i}, x_{j}\right)+\alpha x_{i}\left(1-I\left(x_{i}, x_{j}\right)\right) \\
w_{i}^{\mathcal{N}}\left(x_{i}, x_{j}\right) & =75 \alpha I\left(x_{i}, x_{j}\right)+25 \alpha\left(1-I\left(x_{i}, x_{j}\right)\right)
\end{aligned}
$$

and since for all disclosure rules $\phi \neq \mathcal{T}$, it must be that $x=\left(\beta^{\phi}\right)^{-1}(b)$, we have the wages described in the main text.

\section{A.3 Instruction set}

We reproduce the instructions used in our experiment. All instructions included screenshots of the different stages of the experiment to facilitate comprehension of the experimental environment. The instructions for the different treatments differed only in a key sentence and screenshot in the third page, as well as how the information was revealed in the examples at the end. The key sentence was always underlined in every version shown to subjects.

To minimize the number of pages, we reproduce the different key page 3 sentences below:

$\mathcal{A}$ : "Firms only know the bids of both workers and the identity of the winner and loser."

$\mathcal{W}$ : "Firms only know the winning bid and the identity of the winner."

$\mathcal{S}$ : "Firms only know the losing bid and the identity of the loser."

$\mathcal{T}$ : "Firms will know what the value of the stage 1 prize to either worker is."

$\mathcal{N}$ : "Firms only know the identity of the winner and loser." 
The instructions for the $\mathcal{B}$ treatment did not include (or make a reference to) Stage 2 , or firms. The examples had the same private values and bids, but no stage 2 market, and payoffs in the examples were adjusted accordingly.

We present the instructions used for the $\mathcal{T}$ treatment, as well as the instructions for the belief elicitation treatment. The instruction set for the latter treatment incorporated the instructions for the original treatment; we will not reproduce that section for the sake of brevity.

\section{A.3.1 Instruction set: $\mathcal{T}$}

\section{Instruction set}

Welcome to our experiment. Please read these instructions carefully, as your payment will depend on your decisions, as well as the decisions of other people in the room.

Your payoffs during the experiment will be denominated in Experimental Currency Units (ECU). Once the experiment is finished, we will convert your payoff from ECU to pounds and pay you in cash. $3 \mathrm{ECU}$ are worth $£ 1$. You will also receive $£ 10$ for participating.

This experiment will be divided into 5 practice rounds and 35 real rounds. The experiment you are about to participate in will involve four people, two workers (worker A and worker B) and two firms (firm 1 and firm 2).

Your role in this experiment will be that of a firm. You will retain that role throughout the experiment.

At the beginning of each round, the computer will randomly match two workers and two firms. It is possible, though very unlikely, that you will be paired with the same three people in consecutive rounds.

All rounds of the experiment will work in the same way. We will now describe the way in which each round of the experiment works.

Each round of the experiment is divided into two stages. We now describe each stage in turn.

\section{Stage 1}

Workers bid for the prize in an auction. Workers can bid any amount between 0.00 and 100.00 (maximum of two decimal places). The winner of the auction is the person who bids the highest amount.

If there is a tie, the computer will flip a virtual coin to decide which worker wins the auction.

When bidding, each worker will know his own value of the prize, but each worker will not know the other worker's value.

The value of the prize to either worker is determined randomly by the computer. This value is a number between 0.01 and 100.00 (in increments of 0.01 ), where each number is equally likely to be drawn. 


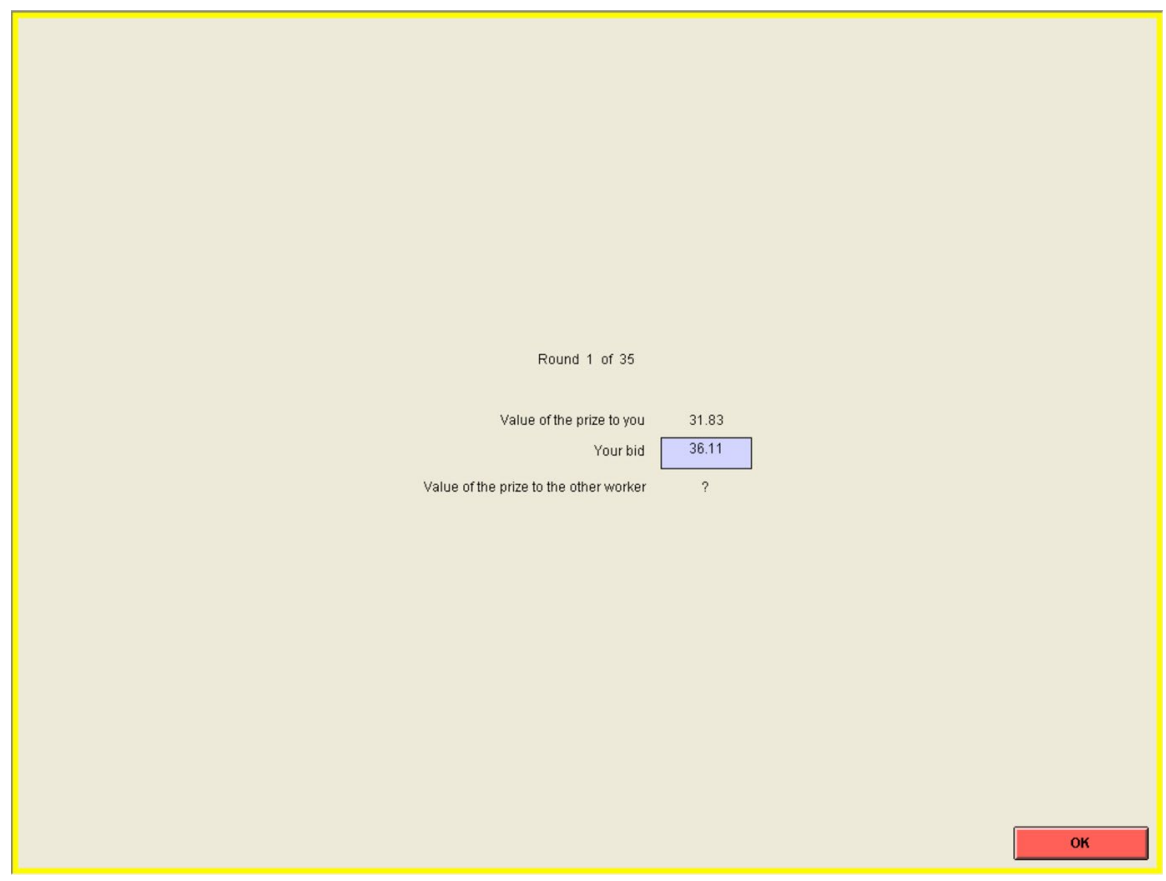

The payoff to the winner of the auction will be equal to the value of the prize minus the bid.

The payoff to the loser of the auction will be zero.

\section{Stage 2}

In Stage 2, the firms will enter an auction to hire the workers.

They will be told of all the bids in Stage 1's auction and the corresponding bidders.

They will offer wages to both the winner and the loser of the Stage 1 auction. 


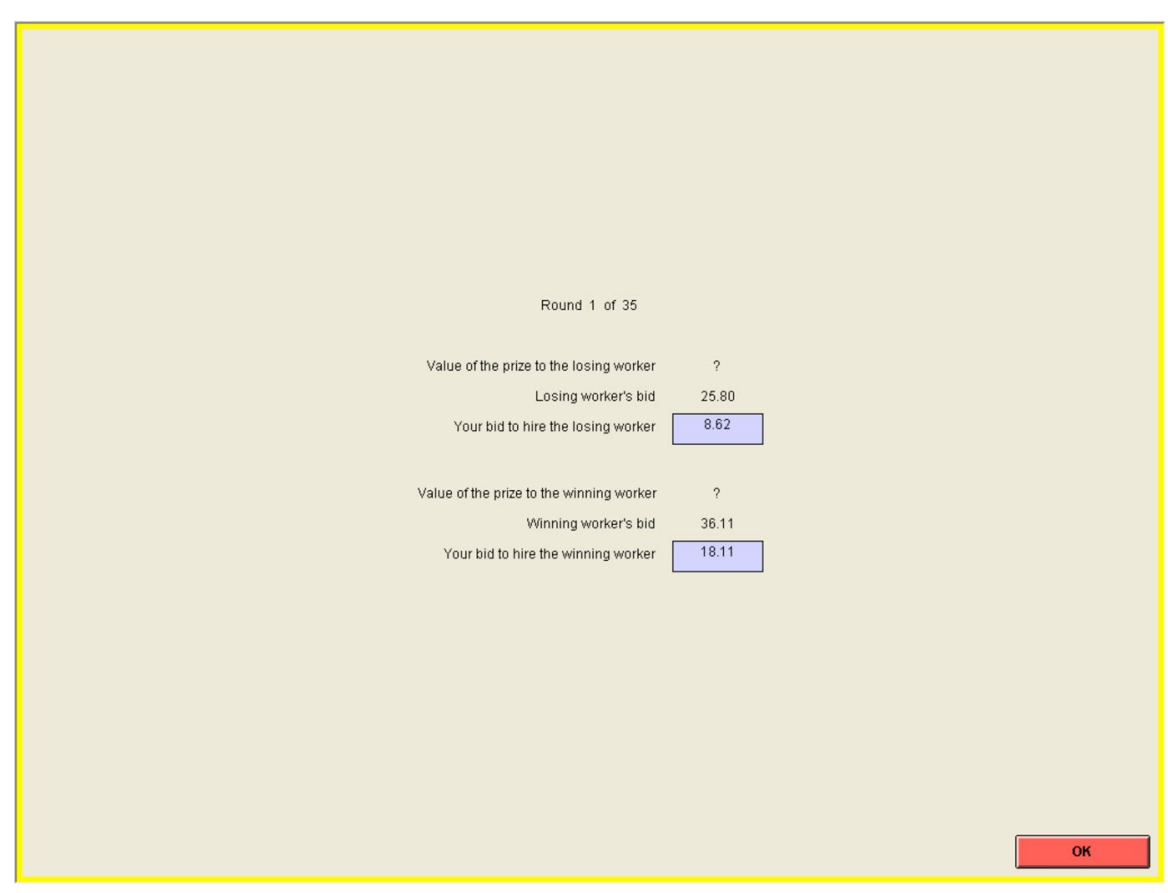

The firm that makes the highest wage offer to a given worker will hire that worker and pay him/her that wage.

It is possible for a firm to hire both workers, if that firm makes the highest wage bid for both workers.

If a firm hires a worker, that firm will gain a payoff equal to $40 \%$ the value that worker assigns to the stage 1 prize. For example, if a worker values the prize at $30 \mathrm{ECU}$, that worker is worth $12 \mathrm{ECU}$ to a firm.

However, the firms do not know what the value of the stage 1 prize to either worker is. Firms only know the bids of both workers and the identity of the winner and loser.

The two firms must make a separate wage bid for the winner and the loser of the first stage auction. The firm that makes the highest bid for a given worker will hire that worker and pay the worker that wage. The firm that makes the lowest bid for a given worker will not hire that worker. In case of a tie, the computer will flip a virtual coin to decide which firm hires that worker.

At the end of the round, firms and workers will receive information about the outcome of the auctions and their final payoffs. 
The following is the final payoff screen for a worker at the end of a period:

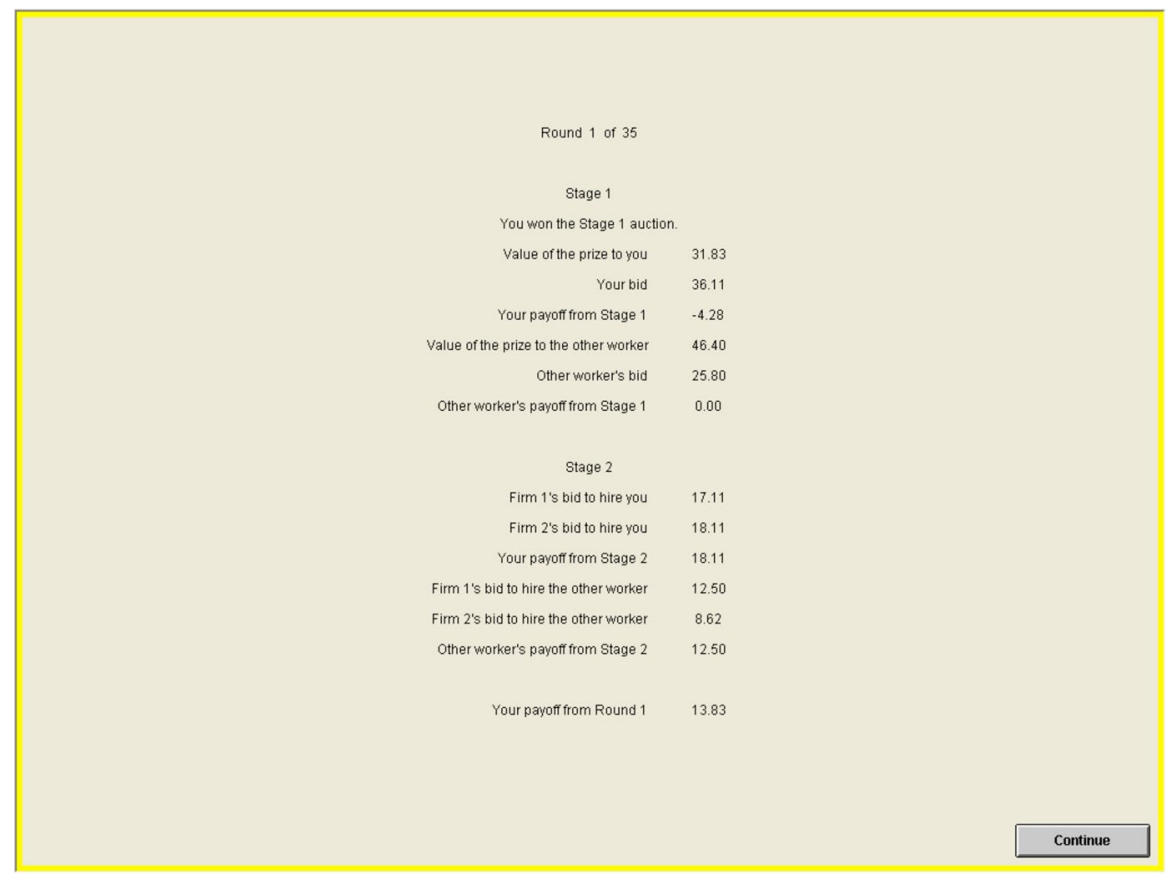

And the following is the payoff screen for a firm at the end of a period:

Round 1 of 35

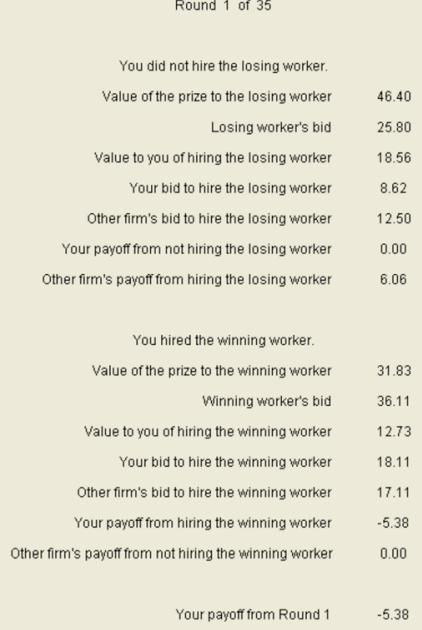


To fix ideas, consider the following examples.

\section{Example 1:}

In Stage 1, worker A has a value of 65 and worker B has a value of 70 . Worker A bids 80 and worker B bids 62. Worker A wins the auction and pays 80, thus having a net payoff of $65-80=-15$. Worker B lost the auction and has a payoff of 0 .

In Stage 2, both firms observe the two bids and the corresponding bidders. That is, they know worker A bid 80 and worker B bid 62. Firm 1 makes a bid of 43 for worker A and a bid of 24 for worker B. Firm 2 bids 30 for worker A and bids 25 for worker B.

Firm 1 had the highest bid for worker A, therefore it hires worker A. Firm 2 made the highest bid for worker B, therefore it hires worker B. The final payoffs for the four players are:

- Worker A gets a payoff of -15 from Stage 1 and a payoff of 43 from Stage 2 for a total of 28 .

- Worker B gets a payoff of 0 from Stage 1 and a payoff of 25 from Stage 2 for a total of 25 .

- Firm 1 gets a payoff of $(0.40 \times 65)-43=-17$.

- Firm 2 gets a payoff of $(0.4 \times 70)-25=3$.

\section{Example 2:}

In Stage 1, worker A has a value of 54 and worker B has a value of 17 . Worker A bids 46 and worker B bids 10 . Worker $A$ wins the auction and pays 46 , thus having a net payoff of $54-46=8$. Worker B lost the auction and has a payoff of 0 .

In Stage 2, both firms observe the two bids and the corresponding bidders. That is, they know worker A bid 46 and worker B bid 10. Firm 1 makes a bid of 15 for worker A and a bid of 6 for worker B. Firm 2 bids 12 for worker A and bids 5 for worker B.

Firm 1 had the highest bid for worker A, therefore it hires worker A. Firm 1 also made the highest bid for worker B, therefore it hires worker B. The final payoffs for the four players are:

- Worker A gets a payoff of 8 from Stage 1 and a payoff of 15 from Stage 2 for a total of 23.

- Worker B gets a payoff of 0 from Stage 1 and a payoff of 6 from Stage 2 for a total of 6 .

- Firm 1 gets a payoff of $(0.40 \times 54)-15+(0.40 \times 17)-6=6.6+0.8=7.4$.

- Firm 2 gets a payoff of 0 .

\section{Example 3:}

In Stage 1, worker A has a value of 33 and worker B has a value of 48 . Worker A bids 46 and worker B bids 55. Worker B wins the auction and pays 55, thus having a net payoff of $48-55=-7$. Worker A lost the auction and has a payoff of 0 . 
In Stage 2, both firms observe the two bids and the corresponding bidders. That is, they know worker A bid 46 and worker B bid 55. Firm 1 makes a bid of 5 for worker A and a bid of 6 for worker B. Firm 2 bids 4 for worker A and bids 7 for worker B.

Firm 1 had the highest bid for worker A, therefore it hires worker A. Firm 2 made the highest bid for worker B, therefore it hires worker B. The final payoffs for the four players are:

- Worker A gets a payoff of 0 from Stage 1 and a payoff of 5 from Stage 2 for a total of 5 .

- Worker B gets a payoff of -7 from Stage 1 and a payoff of 7 from Stage 2 for a total of 0 .

- Firm 1 gets a payoff of $(0.40 \times 33)-5=8.2$.

- Firm 2 gets a payoff of $(0.40 \times 48)-7=12.2$.

Your payment for this experiment will be the sum of payments from three rounds, which the computer will draw at random. Each round is equally likely to be chosen.

\section{A.3.2 Instruction set: belief elicitation}

\section{Instruction set}

Welcome to our experiment. Please read these instructions carefully, as your payment will depend on your decisions.

Your task in this experiment will be to make predictions on the basis of choices made by people who took part in an earlier experiment.

You will be paid for the accuracy of your predictions: the more accurate your guesses are, the more money you will earn.

Before we explain what you will have to predict, we would like you to read the instructions the people who took part in the original experiment read. Those instructions follow this page. They are printed in yellow paper.

Please take $10 \mathrm{~min}$ to read the original instructions. The instructions for your task follow at the end.

In the present experiment, you will be playing the role of the firm. However, you will not be interacting with anyone in the room.

In each period, you will see the bids from the Stage 1 auction from participants who played the role of worker in an experimental session that took place sometime between December 2013 and January 2014. These participants are not present in this room.

In each period, you will have to make two predictions: one for the value of the prize to the winning worker, and another for the value of the prize to the losing worker. You will be able to see the bids that each worker made in Stage 1 of that round before you make your predictions.

The closer your prediction is to the actual value of the prize for a given worker, the more money you will earn.

Your payoff from each prediction is calculated based on the following formula: 
Prediction payoff (in tokens): 10,000 - (true value - predicted value) ${ }^{2}$

For example, suppose that you guessed that, in a given period, the value to a worker was 35.

- If the true value was 35 , then your payoff $=10,000-(35-35)^{2}=10,000$.

- If the true value was 15 , then your payoff $=10,000-(15-35)^{2}=10,000$ $-400=9600$.

- If the true value was 90 , then your payoff $=10,000-(90-35)^{2}=10,000$ $-3025=6975$.

At the end of each period, you will receive feedback about what the actual value of the prize was for both workers, and your payoff for that period.

You will see the same sequence of bids that an actual participant playing the role of a firm saw over the course of the 35 experimental periods.

Once you make predictions for each of the 35 periods in the original experiment, the computer will select three periods at random, which will be the basis for your payment.

This means you will be paid on the basis of six predictions. 10,000 tokens $=£ 1$. You will also earn $£ 4$ for participating.

\section{A.4 Supplementary analysis}

Table 8 displays the Chi-squared values and $\mathrm{p}$ values from revenue comparisons related to the estimates from specification (1) in Table 2.

Table 9 displays GLS regression estimates of the bid placed by worker $i$ in experimental period $t, b_{i, t}$ on that worker's private value in that period, $v_{i, t}$, and dummy interactions with the relevant treatments and their corresponding dummy intercepts; the omitted treatment is $\mathcal{B}$. The first specification only includes treatment dummies and their interactions with $v_{i, t}$. The second specification also includes a linear time trend. The estimated coefficients are unchanged, but we do detect a significant time trend. We rely on the first specification for hypothesis testing purposes, as we test differences in intercepts and the presence of the time trend will alter the economic interpretation of the intercept.

Our main interest, as explained in the text, is on comparative static effects of disclosure rules. For the sake of completeness, we include the tests for the point predictions of the model. We find that the empirical bidding functions are significantly different from their theoretical counterparts; in particular the intercepts of the estimated bidding functions from limited disclosure treatments are significantly smaller than predicted.

We start by looking at the $\mathcal{B}$ treatment, which is the omitted category in the regression results. A joint test of equality of the coefficient and slope to the benchmark predictions ( 0 and 0.5 , respectively) yielded statistically significant differences $\left(\chi^{2}(2)=1769.03, p<0.001\right)$. Given that the estimated constant is not significantly different to zero $\left(\chi^{2}(2)=0.91, p=0.340\right)$, the likely source of the difference is the estimated slope $\left(\chi^{2}(2)=126.10, p<0.001\right)$. 
Table 8 Chi-squared values and $\mathrm{p}$ values from revenue comparisons

\begin{tabular}{llllll}
\hline & $\mathcal{T}$ & $\mathcal{W}$ & $\mathcal{S}$ & $\mathcal{A}$ & $\mathcal{N}$ \\
\hline $\mathcal{B}$ & $(0.04 ; 0.836)$ & $(32.77 ; 0.000)$ & $(1.97 ; 0.161)$ & $(9.64 ; 0.002)$ & $(2.51 ; 0.113)$ \\
$\mathcal{T}$ & & $(13.74 ; 0.000)$ & $(1.73 ; 0.189)$ & $(7.15 ; 0.008)$ & $(2.43 ; 0.119)$ \\
$\mathcal{W}$ & & $(4.06 ; 0.044)$ & $(0.02 ; 0.881)$ & $(0.28 ; 0.600)$ \\
$\mathcal{S}$ & & & $(1.88 ; 0.171)$ & $(0.36 ; 0.549)$ \\
$\mathcal{A}$ & & & & $(0.15,0.703)$ \\
\hline
\end{tabular}

Table 9 Random Effect GLS estimates of workers' bidding function for each treatment

\begin{tabular}{lllll}
\hline $\mathrm{DV}: b_{i, t}$ & $(1)$ & & $(2)$ & \\
\hline $\mathcal{T} \times v_{i, t}$ & -0.06 & $(0.04)$ & -0.06 & $(0.04)$ \\
$\mathcal{T}$ & $2.38^{* *}$ & $(1.17)$ & $2.42^{* *}$ & $(1.14)$ \\
$\mathcal{W} \times v_{i, t}$ & 0.04 & $(0.02)$ & $0.04^{* * *}$ & $(0.02)$ \\
$\mathcal{W}$ & $3.18^{* * *}$ & $(0.56)$ & $3.28^{* * *}$ & $(0.59)$ \\
$\mathcal{S} \times v_{i, t}$ & $-0.07^{* * *}$ & $(0.02)$ & $-0.07^{* * *}$ & $(0.02)$ \\
$\mathcal{S}$ & $7.40^{* * *}$ & $(1.28)$ & $7.39^{* * *}$ & $(1.29)$ \\
$\mathcal{A} \times v_{i, t}$ & -0.03 & $(0.04)$ & -0.03 & $(0.04)$ \\
$\mathcal{A}$ & $8.77^{* * *}$ & $(1.38)$ & $8.69^{* * *}$ & $(1.35)$ \\
$\mathcal{N} \times v_{i, t}$ & -0.02 & $(0.02)$ & -0.02 & $(0.02)$ \\
$\mathcal{N}$ & $6.37^{* * *}$ & $(1.54)$ & $6.33^{* * *}$ & $(1.54)$ \\
$v_{i, t}$ & $0.75^{* * *}$ & $(0.02)$ & $0.75^{* * *}$ & $(0.02)$ \\
Period & - & & $-0.08^{* * *}$ & $(0.02)$ \\
Constant & 0.31 & $(0.33)$ & $1.75^{* * *}$ & $(0.59)$ \\
$\mathrm{N}$ & 4,410 & & 4,410 & \\
$R^{2}$ & 0.87 & & 0.87 & \\
\hline
\end{tabular}

Session-level clustered SEs in parentheses ***,** $: p<0.01, p<0.05$

We find that the estimated bidding function in $\mathcal{T}$ is significantly different to predictions $\left(\chi^{2}(2)=262.58, p<0.001\right)$. This difference is caused by significant differences between predicted and estimated intercept $\left(\chi^{2}(2)=5.79, p=0.016\right)$, as well as slope $\left(\chi^{2}(2)=21.65, p<0.001\right)$.

We also find that the estimated bidding function in $\mathcal{W}$ is significantly different to predictions $\left(\chi^{2}(2)=17815.69, p<0.001\right)$. The critical difference appears to come from the estimated intercept $\left(3.49, \chi^{2}(2)=58.87, p<0.001\right)$, which is significantly different from the point prediction, although the estimated slope is quite close to prediction $\left(0.8, \chi^{2}(2)=2.40, p=0.121\right)$.

In the case of $\mathcal{S}$, the empirical bidding function is different from prediction $\left(\chi^{2}(2)=2067.43, p<0.001\right)$, but here the qualitative nature of the difference is rather different: the empirical bidding function is steeper than predicted ( 0.67 vs. $\left.0.2, \chi^{2}(2)=1693.49, p<0.001\right)$, but the estimated intercept is much smaller than 
what theory predicts $\left(7.71\right.$ vs. $\left.60, \chi^{2}(2)=1776.79, p<0.001\right)$. In other words, workers are not overbidding by as much as they should when then get a bad private valuation for the stage 1 good.

The same is true for the $\mathcal{A}$; the joint test of equality of the estimated slope and intercept to the predicted values rejects the null at highly significant levels $\left(\chi^{2}(2)=7080.02, p<0.001\right)$. This is driven by a large difference between predicted and estimated intercept (40 vs. 9.08, $\chi^{2}(1)=535.62, p<0.001$ ), as well as a large difference between predicted and estimated slope ( 0.5 vs. 0.71 , $\left.\chi^{2}(1)=30.15, p<0.001\right)$.

Table 10 reports the test statistics and $\mathrm{p}$ values for all slope and intercept and joint test comparisons across all treatments.

Table 11 displays the GLS regression estimates of wages as a function of winning the stage 1 auction. We report on a specification with and without a time trend. $\mathcal{T}$ is the omitted category; Winner equals one if worker $i$ won the stage- 1 auction in period $t$.

Table 10 Hypothesis tests on worker bidding functions

\begin{tabular}{|c|c|c|c|c|c|}
\hline \multicolumn{6}{|c|}{ Intercept } \\
\hline & W & $\mathrm{S}$ & A & $\mathrm{N}$ & $\mathrm{T}$ \\
\hline $\mathrm{S}$ & $10.21,0.001$ & & & & \\
\hline A & $15.70,<0.001$ & $0.57,0.452$ & & & \\
\hline $\mathrm{N}$ & $4.21,0.042$ & $0.27,0.600$ & $1.41,0.235$ & & \\
\hline $\mathrm{T}$ & $0.43,0.511$ & $9.00,0.003$ & $13.42,<0.001$ & $4.52,0.034$ & \\
\hline B & $32.00,<0.001$ & $33.23,<0.001$ & $40.61,<0.001$ & $17.04,<0.001$ & $4.16,0.041$ \\
\hline \multicolumn{6}{|c|}{ Slope } \\
\hline & W & $\mathrm{S}$ & A & $\mathrm{N}$ & $\mathrm{T}$ \\
\hline $\mathrm{S}$ & $54.90,<0.001$ & & & & \\
\hline A & $3.41,0.065$ & $0.98,0.322$ & & & \\
\hline $\mathrm{N}$ & $35.04,<0.001$ & $18.87,<0.001$ & $0.09,0.767$ & & \\
\hline $\mathrm{T}$ & $6.30,0.012$ & $0.08,0.781$ & $0.27,0.606$ & $1.02,0.312$ & \\
\hline B & $2.60,0.107$ & $9.06,0.003$ & $0.61,0.435$ & $1.10,0.294$ & $1.96,0.161$ \\
\hline \multicolumn{6}{|c|}{ Joint } \\
\hline & W & $\mathrm{S}$ & A & $\mathrm{N}$ & $\mathrm{T}$ \\
\hline $\mathrm{S}$ & $63.17,<0.001$ & & & & \\
\hline A & $51.09,<0.001$ & $7.46,0.024$ & & & \\
\hline $\mathrm{N}$ & $35.08,<0.001$ & $22.22,<0.001$ & $1.79,0.409$ & & \\
\hline $\mathrm{T}$ & $53.92,<0.001$ & $16.52,<0.001$ & $114.63,<0.001$ & $11.56,0.003$ & \\
\hline B & $179.03,<0.001$ & $33.23,<0.001$ & $118.98,<0.001$ & $17.04,<0.001$ & $4.98,0.083$ \\
\hline
\end{tabular}


Table 11 Estimates of workers' wages as a function of stage 1 auction outcome

\begin{tabular}{lllll}
\hline DV: $b_{i, t}$ & $(1)$ & & $(2)$ & \\
\hline $\mathcal{W} \times$ Winner & 0.85 & $(1.22)$ & 0.85 & $(1.22)$ \\
$\mathcal{W}$ & $-1.97^{* * *}$ & $(0.66)$ & $-1.97^{* * *}$ & $(0.66)$ \\
$\mathcal{S} \times$ Winner & $-3.75^{* * *}$ & $(1.35)$ & $-3.76^{* * *}$ & $(1.35)$ \\
$\mathcal{S}$ & 0.63 & $(1.55)$ & 0.63 & $(1.55)$ \\
$\mathcal{A} \times$ Winner & $-2.83^{* * *}$ & $(0.81)$ & $-2.84^{* * *}$ & $(0.81)$ \\
$\mathcal{A}$ & 0.42 & $(0.67)$ & 0.42 & $(0.67)$ \\
$\mathcal{N} \times$ Winner & $-2.81^{* *}$ & $(1.13)$ & $-2.82^{* *}$ & $(1.13)$ \\
$\mathcal{N}$ & -1.43 & $(0.90)$ & -1.43 & $(0.90)$ \\
Winner & $12.33^{* * *}$ & $(0.81)$ & $12.34^{* * *}$ & $(0.81)$ \\
Period & & & -0.03 & $(0.02)$ \\
Constant & $12.54^{* * *}$ & $(0.33)$ & $13.02^{* * *}$ & $(0.49)$ \\
$\mathrm{N}$ & 3,150 & & 3,150 & \\
$R^{2}$ & 0.32 & & 0.32 & \\
\hline
\end{tabular}

***,** $: p<0.01, p<0.05$

Session-level clustered SEs in parentheses

\section{References}

Arrow KJ (1971) Essays in the theory of risk-bearing. Markham Publishing Group, Chicago

Bos O, Gomez-Martinez F, Onderstal S, Truyts T (2018) Signalling in auctions: experimental evidence. CESifo Working Paper Series 7261, CESifo

Cooper DJ, Kagel JH (2005) Are two heads better than one? Team versus individual play in signaling games. Am Econ Rev 95:477-509

Cooper DJ, Kagel JH (2009) The role of context and team play in cross-game learning. J Eur Econ Assoc 7:1101-1139

Cooper DJ, Garvin S, Kagel JH (1997) Signaling and adaptive learning in an entry limit pricing game. RAND J Econ 28:662-683

Cox James C, Smith Vernon L, Walker James M (1985) Experimental development of sealed-bid auction theory; calibrating controls for risk aversion. Am Econ Rev 75:160-165

Cox James C, Smith Vernon L, Walker James M (1988) Theory and individual behavior of first-price auctions. J Risk Uncertain 1(1):61-99

Das Varma G (2003) Bidding for a process innovation under alternative modes of competition. Int J Ind Organ 21:15-37

Dodonova A, Khoroshilov Y (2014) Preemptive bidding in takeover auctions: an experimental study. Manag Decis Econ 35:216-230

Dufwenberg M, Gneezy U (2000) Price competition and market concentration: an experimental study. Int $\mathrm{J}$ Ind Organ 18(1):7-22

Dufwenberg M, Gneezy U (2002) Information disclosure in auctions: an experiment. J Econ Behav Organ 48(4):431-44

Dworczak P (2017) Mechanism design with aftermarkets: cutoff mechanisms. Mimeo

Engelbrecht-Wiggans R (1989) The effect of regret on optimal bidding in auctions. Manag Sci 35(6):685-92

Engelbrecht-Wiggans R, Katok E (2005) Regret in auctions: theory and evidence. Econ Theory 33(1):81-101

Filiz-Ozbay E, Ozbay EY (2007) Auctions with anticipated regret: theory and experiment. Am Econ Rev 97(4):1407-1418

Filiz-Ozbay E, Lopez-Vargas K, Ozbay EY (2015) Multi-object auctions with resale: theory and experiment. Games Econ Behav 89:1-16 
Fischbacher U (2007) z-Tree-Zurich toolbox for Readymade Economic Experiments. Exp Econ 10(2):171-178

Fishman M (1988) A theory of preemptive takeover bidding. Rand J Econ 19:88-101

Fonseca MA, Normann H-T (2012) Explicit vs. tacit collusion-the impact of communication in oligopoly experiments. Eur Econ Rev 56(8):1759-1772

Georganas S (2011) English auctions with resale: an experimental study. Games Econ Behav 73:147-166

Georganas S, Kagel JH (2011) Asymmetric auctions with resale: an experimental study. J Econ Theory 146:359-371

Giovannoni F, Makris M (2014) Reputational Bidding. Int Econ Rev 55:693-710

Goeree J (2003) Bidding for future: signaling in auctions with an aftermarket. J Econ Theory 108:345-364

Goeree J, Holt CA (2002) Quantal response equilibrium and overbidding in private-value auctions. J Econ Theory 104:247-272

Greiner B (2015) Subject pool recruitment procedures: organizing experiments with ORSEE. J Econ Sci Assoc 1(1):114-125

Güth W, Ivanova-Stenzel R, Wolfstetter E (2005) Bidding behavior in asymmetric auctions: an experimental study. Eur Econ Rev 49(7):1891-1913

Haile P (2003) Auctions with private uncertainty and resale opportunities. J Econ Theory 108:72-100

Isaac R, Walker J (1985) Information and conspiracy in sealed bid auctions. J Econ Behav Organ 6:139-159

Jeitschko TD, Normann HT (2012) Signaling in deterministic and stochastic settings. J Econ Behav Organ 82:39-55

Kagel JH (1995) Auctions: a survey of experimental research. In: Kagel JH, Roth AE (eds) The handbook of experimental economics

Kagel JH, Levin D (2008) Auctions: a survey of experimental research, 1995-2008. Handb Exp Econ 2:2

Katzman B, Rhodes-Kropf M (2008) The consequences of information revealed in auctions. Appl Econ Res Bull 2:53-87

Kübler D, Müller W, Normann HT (2008) Job market signaling and screening: an experimental comparison. Games Econ Behav 64:219-236

Lange A, List JA, Price MK (2011) Auctions with resale when private values are uncertain: evidence from the lab and field. Int J Ind Organ 29:54-64

Miller R, Plott C (1985) Product quality signaling in experimental markets. Econometrica 53:837-872

Molnar J, Virag G (2008) Revenue maximizing auctions with market interaction and signaling. Econ Lett 99:360-363

Ockenfels A, Selten R (2005) Impulse balance equilibrium and feedback in first price auctions. Games Econ Behav 51(1):155-70

Offerman T, Sonnemans J, van de Kuilen G, Wakker PP (2009) A truth serum for non-Bayesians: correcting proper scoring rules for risk attitudes. Rev Econ Stud 76:1461-1489

Pagnozzi M, Saral KJ (2017) Demand reduction in multi-object auctions with resale: an experimental analysis. Econ J 127(607):2702-2729

Rabin M (2000) Risk aversion and expected utility theory: a calibration theorem. Econometrica 68(5):1281-1292

Salmon TC, Wilson BJ (2008) Second chance offers versus sequential auctions: theory and behavior. Econ Theory 34:47-67

Smith VL, Walker JM (1993) Rewards, experience and decision costs in first price auctions. Econ Inq 31(2):237-245

Publisher's Note Springer Nature remains neutral with regard to jurisdictional claims in published maps and institutional affiliations. 